\title{
Spider phylogenomics: untangling the Spider Tree of Life
}

Nicole L Garrison, Juanita Rodriguez, Ingi Agnarsson, Jonathan A Coddington, Charles E Griswold, Christopher A Hamilton, Marshal Hedin, Kevin M Kocot, Joel M Ledford, Jason E Bond

Spiders (Order Araneae) are massively abundant generalist arthropod predators that are found in nearly every ecosystem on the planet and have persisted for over 380 million years. Spiders have long served as evolutionary models for studying complex mating and web spinning behaviors, key innovation and adaptive radiation hypotheses, and have been inspiration for important theories like sexual selection by female choice. Unfortunately, past major attempts to reconstruct spider phylogeny typically employing the "usual suspect" genes have been unable to produce a well-supported phylogenetic framework for the entire order. To further resolve spider evolutionary relationships we have assembled a transcriptome-based data set comprising 70 ingroup spider taxa. Using maximum likelihood and shortcut coalescence-based approaches, we analyze eight data sets, the largest of which contains 3,398 gene regions and 696,652 amino acid sites forming the largest phylogenomic analysis of spider relationships produced to date. Contrary to long held beliefs that the orb web is the crowning achievement of spider evolution, ancestral state reconstructions of web type support a phylogenetically ancient origin of the orb web and diversification analyses show that the mostly ground-dwelling, web-less RTA clade diversified faster than orb weavers. Consistent with molecular dating estimates we report herein, this may reflect a major increase in biomass of non-flying insects during the Cretaceous Tertiary Revolution 125-90 million years ago favoring diversification of spiders that feed on cursorial rather than flying prey. Our results also have major implications for our understanding of spider systematics. Phylogenomic analyses corroborate several wellaccepted high level groupings: Opisthothele, Mygalomorphae, Atypoidina, Aviculariodea, Theraphosidina, Araneomorphae, Entelygynae, Araneoidea, the RTA - clade, Dionycha and the Lycosoidea. Alternatively, our results challenge the monophyly of Eresoidea, Orbiculariae, and Deinopoidea. The composition of the major Paleocribellate and Neocribellate clades, the basal divisions of Araneomorphae, appear to be falsified. Traditional Haplogynae, and even the new concept of Synspermiata, need revision after the departure of Filistatidae and Leptonetidae from the haplogyne clade. The sister pairing of filistatids with hypochilids, implies that some peculiar features of each family may in fact be synapomorphic for the pair. Leptonetids now are seen as a possible sister group to the Entelegynae, illustrating possible intermediates in the evolution of the more complex 
entelegyne genitalic condition, spinning organs and respiratory organs. 


\title{
Spider Phylogenomics: Untangling the Spider Tree of Life
}

Nicole L. Garrison ${ }^{1}$, Juanita Rodriguez ${ }^{1}$, Ingi Agnarsson ${ }^{2}$, Jonathan A. Coddington $^{3}$, Charles E. Griswold ${ }^{4}$, Chris A. Hamilton ${ }^{1}$, Marshal Hedin ${ }^{5}$, Kevin M. Kocot ${ }^{6}$, Joel M. Ledford ${ }^{7}$, and Jason E. Bond ${ }^{* 1}$

\author{
${ }^{1}$ Department of Biological Sciences and Auburn University Museum of Natural History, \\ Auburn University \\ ${ }^{2}$ Department of Biology, University of Vermont \\ ${ }^{3}$ Department of Entomology, National Museum of Natural History, Smithsonian \\ Institution, Washington, DC \\ ${ }^{4}$ Arachnology, California Academy of Sciences \\ ${ }^{5}$ Department of Biology, San Diego State University \\ ${ }^{6}$ Department of Biological Sciences, University of Alabama \\ ${ }^{7}$ Department of Plant Biology, University of California Davis
}

15 ABSTRACT

Spiders (Order Araneae) are massively abundant generalist arthropod predators that are found in nearly every ecosystem on the planet and have persisted for over 380 million years. Spiders have long served as evolutionary models for studying complex mating and web spinning behaviors, key innovation and adaptive radiation hypotheses, and have been inspiration for important theories like sexual selection by female choice. Unfortunately, past major attempts to reconstruct spider phylogeny typically employing the "usual suspect" genes have been unable to produce a well-supported phylogenetic framework for the entire order. To further resolve spider evolutionary relationships we have assembled a transcriptomebased data set comprising 70 ingroup spider taxa. Using maximum likelihood and shortcut, or two-step, coalescence-based approaches, we analyze eight data sets, the largest of which contains 3,398 gene regions and 696,652 amino acid sites forming the largest phylogenomic analysis of spider relationships produced to date. Contrary to long held beliefs that the orb web is the crowning achievement of spider evolution, ancestral state reconstructions of web type support a phylogenetically ancient origin of the orb web and diversification analyses show that the mostly ground-dwelling, web-less RTA clade diversified faster than orb weavers. Consistent with molecular dating estimates we report herein, this may reflect a major increase in biomass of non-flying insects during the Cretaceous Terrestrial Revolution 125-90 million years ago favoring diversification of spiders that feed on cursorial rather than flying prey. Our results also have major implications for our understanding of spider systematics. Phylogenomic analyses corroborate several well-accepted high level groupings: Opisthothele, Mygalomorphae, Atypoidina, Aviculariodea, Theraphosidina, Araneomorphae, Entelygynae, Araneoidea, the RTA - clade, Dionycha and the Lycosoidea. Alternatively, our results challenge the monophyly of Eresoidea, Orbiculariae, and Deinopoidea. The composition of the major Paleocribellate and Neocribellate clades, the basal divisions of Araneomorphae, appear to be falsified. Traditional Haplogynae need revision after the departure of Filistatidae and Leptonetidae from the haplogyne clade, as our findings appear to support the newly conceived Synspermiata. The sister pairing of filistatids with hypochilids implies that some peculiar features of each family may in fact be synapomorphic for the pair. Leptonetids now are seen as a possible sister group to the Entelegynae, illustrating possible intermediates in the evolution of the more complex entelegyne genitalic condition, spinning organs and respiratory organs.

Keywords: Araneae, Cretaceous Terrestrial Revolution, Molecular Systematics, Spider phylogeny, Web evolution

*Corresponding Author: 101 Rouse Life Sciences, Auburn University , AL, 36849, USA, jbond@ auburn.edu 


\section{Authorship Statement}

Order of authorship following the second author (JR) determined alphabetically through senior corresponding author (JEB).

\section{INTRODUCTION}

Spiders (Order Araneae; Figure 1) are a prototypical, hyperdiverse arthropod group comprising $>45,000$ described species (World Spider Catalog, 2016) distributed among 3,958 genera and 114 families; by some estimates the group may include $>120,000$ species (Agnarsson et al., 2013). Spiders are abundant, generalist predators that play dominant roles in almost every terrestrial ecosystem. The order represents an ancient group that has continued to diversify taxonomically and ecologically since the Devonian ( $>380$ mya). They are relatively easy to collect and identify, and are one of few large arthropod orders to have a complete online taxonomic catalog with synonymies and associated literature (World Spider Catalog, 2016).

In addition to their remarkable ecology, diversity, and abundance, spiders are known for the production of extraordinary biomolecules like venoms and silks as well as their utility as models for behavioral and evolutionary studies (reviewed in Agnarsson et al., 2013). Stable and complex venoms have evolved over millions of years to target predators and prey alike. Although few are dangerous to humans, spider venoms hold enormous promise as economically important insecticides and therapeutics (Saez et al., 2010; King and Hardy, 2013). Moreover, no other animal lineage can claim a more varied and elegant use of silk. A single species may have as many as eight different silk glands, producing a variety of super-strong silks deployed in almost every aspect of a spider's life (Garb and Penney, 2013): safety lines, dispersal, reproduction (sperm webs, eggsacs, pheromone trails), and prey capture (Blackledge et al., 2011). Silken prey capture webs, particularly the orb, have long been considered a key characteristic contributing to the ecological and evolutionary success of this group (reviewed in Bond and Opell, 1998). Moreover, spider silks are promising biomaterials, already benefiting humans in myriad ways - understanding the phylogenetic basis of such super-materials will facilitate efforts to reproduce their properties in biomimetic materials like artificial nerve constructs, implant coatings, and drug delivery systems (Schacht and Scheibel, 2014; Blackledge et al., 2011).

The consensus on major spider clades has changed relatively little in the last two decades since the summary of Coddington and Levi (1991) and Coddington (2005). Under the classical view, Araneae comprises two clades (see Table 1 and Figure 1 for major taxa discussed throughout; node numbers (Figure 1) referenced parenthetically hereafter), Mesothelae (Node 2) and Opisthothelae (Node 3). Mesotheles are sister to all other spiders, possessing a plesiomorphic segmented abdomen and mid-ventral (as opposed to terminal) spinnerets. Opisthothelae contains two clades: Mygalomorphae (Node 4) and Araneomorphae (Node 8). Mygalomorphae is less diverse (6\% of described Araneae diversity) and retains several plesiomorphic features (e.g. two pairs of book lungs, few and biomechanically 'weak' silks (Dicko et al., 2008; Starrett et al., 2012). Within Araneomorphae, Hypochilidae (Paleocribellatae; Node 9) is sister to Neocribellatae, within which Austrochiloidea are sister to the major clades Haplogynae (Node 10) and Entelegynae (Node 11), each weakly to moderately supported by few morphological features. Haplogynes have simple genitalia under muscular control whereas entelegynes have hydraulically activated, complex genitalia, with externally sclerotized female epigyna. Entelegynes comprise multiple, major, hyperdiverse groups, including the "RTA clade" (RTA = retrolateral tibial apophysis, Node 13), its subclade Dionycha (e.g.jumping spiders; Ramírez, 2014, Node 14), and the Orbiculariae - the cribellate and ecribellate orb weavers and relatives (see Hormiga and Griswold, 2014).

Beginning with early higher-level molecular phylogenetic studies, it gradually became clear that major "stalwart" and presumably well-supported spider groups like the Neocribellatae, Haplogynae, Palpimanoidea, Orbiculariae, Lycosoidea, and others (generally only known to arachnologists) were questionable. Subsequent studies focusing on mygalomorph (Hedin and Bond, 2006; Bond et al., 2012) and araneomorph (Blackledge et al., 2009; Dimitrov et al., 2012) relationships continued to challenge the consensus view based largely on morphological data, finding polyphyletic families and ambivalent support for major clades, which were sometimes "rescued" by adding non-molecular data; molecular signal persistently contradicted past verities. In Agnarsson et al. (2013), a meta-analysis of available molecular data failed to recover several major groups such as Araneomorphae, Haplogynae, Orbiculariae, Lycosoidea, and others (Table 1). Although these authors criticized the available molecular data as insufficient, their results actually presaged current spider phylogenomic inferences (Bond et al., 2014). 
Incongruence between the traditional spider classification scheme and (non-phylogenomic) molecular systematics likely has one primary cause: too few data. Non-molecular datasets to date have been restricted to a relatively small set of morphological and/or behavioral characters whereas molecular analyses addressing deep spider relationships have largely employed relatively few, rapidly evolving loci (e.g., 28S and 18S rRNA genes, Histone 3, and a number of mitochondrial DNA markers).

The first analyses of spider relationships using genome-scale data, scored for 40 taxa by Bond et al. (2014) and for 14 taxa by Fernández et al. (2014), considerably refined understanding of spider phylogeny, the former explicitly calling into question long held notions regarding the tempo and mode of spider evolution. Using transcriptome-derived data, Bond et al. (2014) recovered the monophyly of some major groups (araneomorphs and mygalomorphs) but reshuffled several araneomorph lineages (haplogynes, paleocribellates, orbicularians, araneoids (Node 12) and the RTA clade). Notably, Bond et al. (2014) and Fernández et al. (2014) rejected Orbiculariae, which included both cribellate (Deinopoidea) and ecribellate orb weavers (Araneoidea). Instead they suggested either that the orb web arose multiple times, or, more parsimoniously, that it arose once and predated the major diversification of spiders. Despite major advances in understanding of spider phylogeny, only a small percentage of spider families were sampled and monophyly of individual families could not be tested in previous phylogenomic studies. Denser taxon sampling is needed to warrant changes in higher classification and to more definitively address major questions about spider evolution.

Herein, we apply a spider-specific core ortholog approach with significantly increased taxon and gene sampling to produce a more complete and taxon specific set of alignments for phylogenetic reconstruction and assessment of spider evolutionary pattern and process. Existing genome-derived protein predictions and transcriptome sequences from a representative group of spiders and arachnid outgroups were used to create a custom core ortholog set specific to spiders. Taxon sampling was performed to broadly sample Araneae with an emphasis on lineages whose phylogenetic placement is uncertain and included previously sequenced transcriptomes, gene models from completely sequenced genomes, and novel transcriptome sequences generated by our research team. This resulted in a data set comprising 70 spider taxa plus five additional arachnid taxa as outgroups. We test long-held notions that the orb web, in conjunction with ecribellate adhesive threads, facilitated diversification among araneoids and present the most completely sampled phylogenomic data set for spiders to date using an extensive dataset of nearly 3,400 putative genes ( $700 \mathrm{~K}$ amino acids). Further, we test the hypothesis of a non-monophyletic Orbiculariae, assess diversification rate shifts across the spider phylogeny, and provide phylogenomic hypotheses for historically difficult to place spider families. Our results clearly demonstrate that our understanding of spider phylogeny and evolution requires major reconsideration and that several long-held and contemporary morphologically-derived hypotheses are likely destined for falsification.

\section{MATERIALS \& METHODS}

\section{Sampling, Extraction, Assembly}

Spider sequence data representing all major lineages were collected from previously published transcriptomic and genomic resources $(\mathrm{N}=53)$ and supplemented with newly sequenced transcriptomes $(\mathrm{N}=22)$ to form the target taxon set for the current study. Existing sequence data were acquired via the NCBI SRA database (http://www.ncbi.nlm.nih.gov/sra). Raw transcriptome sequences were downloaded, converted to fastq file format, and assembled using Trinity (Grabherr et al., 2011). Genomic data sets in the form of predicted proteins were downloaded directly from the literature (Sanggaard et al., 2014) for downstream use in our pipeline. Newly sequenced spiders were collected from a variety of sources, extracted using the TRIzol total RNA extraction method, purified with the RNeasy mini kit (Qiagen) and sequenced in-house at the Auburn University Core Genetics and Sequencing Laboratory using an Illumina Hi-Seq 2500. This produced 100bp paired end reads for each newly sequenced spider transcriptome, which were then assembled using Trinity. Proteins were predicted from each transcriptome using the program TransDecoder (Haas et al., 2013).

\section{Core Ortholog Approach and Data Processing}

We employed a core ortholog approach for putative ortholog selection and implicitly compared the effect of using a common arthropod core ortholog set and one compiled for spiders; the arthropod core ortholog set was deployed as described in Bond et al. (2014). To generate the spider core ortholog set, we used an all-versus-all BLASTP method (Altschul, Stephen F. et al., 1990) to compare the transcripts of the 
amblypygid Damon variegatus, and the spiders Acanthoscurria geniculata, Dolomedes triton, Ero leonina, Hypochilus pococki, Leucauge venusta, Liphistius malayanus, Megahexura fulva, Neoscona arabesca, Stegodyphus mimosarum, and Uloborus sp.. Acanthoscurria geniculata and Stegodyphus mimosarum were represented by predicted transcripts from completely sequenced genomes while the other taxa were represented by our new Illumina transcriptomes. An e-value cut-off of 10-5 was used. Next, based on the BLASTP results, Markov clustering was conducted using OrthoMCL 2.0 (Li et al., 2003) with an inflation parameter of 2.1 .

The resulting putatively orthologous groups (OGs) were processed with a modified version of the bioinformatics pipeline employed by Kocot et al. (2011). First, sequences shorter than 100 amino acids in length were discarded. Next, each candidate OG was aligned with MAFFT (Katoh, 2005) using the automatic alignment strategy with a maxiterate value of 1,000. To screen OGs for evidence of paralogy, an "approximately maximum likelihood tree" was inferred for each remaining alignment using FastTree 2 (Price et al., 2010). Briefly, this program constructs an initial neighbor-joining tree and improves it using minimum evolution with nearest neighbor interchange (NNI) subtree rearrangement. FastTree subsequently uses minimum evolution with subtree pruning regrafting (SPR) and maximum likelihood using NNI to further improve the tree. We used the "slow" and "gamma" options; "slow" specifies a more exhaustive NNI search, while "gamma" reports the likelihood under a discrete gamma approximation with 20 categories, after the final round of optimizing branch lengths. PhyloTreePruner (Kocot et al., 2013) was then employed as a tree-based approach to screen each candidate OG for evidence of paralogy. First, nodes with support values below 0.95 were collapsed into polytomies. Next, the maximally inclusive subtree was selected where all taxa were represented by no more than one sequence or, in cases where more than one sequence was present for any taxon, all sequences from that taxon formed a monophyletic group or were part of the same polytomy. Putative paralogs (sequences falling outside of this maximally inclusive subtree) were then deleted from the input alignment. In cases where multiple sequences from the same taxon formed a clade or were part of the same polytomy, all sequences but the longest were deleted. Lastly, in order to eliminate orthology groups with poor taxon sampling, all groups sampled for fewer than 7 of the 11 taxa and all groups not sampled for Megahexura fulva (taxon with greatest number of identified OGs) were discarded. The remaining alignments were used to build profile hidden Markov models (pHMMs) for HaMStR with hmmbuild and hmmcalibrate from the HMMER package (Eddy, 2011).

For orthology inference, we employed HaMStR v13.2.3 (Ebersberger et al., 2009), which infers orthology based on predefined sets of orthologs. Translated transcripts for all taxa were searched against the new set of 4,934 spider-specific pHMMs (available for download from the Dryad Data Repository) and an arthropod core ortholog set previously employed in Bond et al. (2014). In the spider core ortholog analysis, the genome-derived Acanthoscurria geniculata OGs were used as the reference protein set for reciprocal best hit scoring. Daphnia pulex was used as the reference species for putative ortholog detection in the arthropod core ortholog analysis. Orthologs sharing a core identification number were pooled together for all taxa and processed using a modified version of the pipeline used to generate the custom spider ortholog set. In both analyses, sequences shorter than 75 amino acids were deleted first. OGs sampled for fewer than 10 taxa were then discarded. Redundant identical sequences were removed with the perl script uniqhaplo.pl (available at http://raven.iab.alaska.edu/ ntakebay/) leaving only unique sequences for each taxon. Next, in cases where one of the first or last 20 characters of an amino acid sequence was an $\mathrm{X}$ (corresponding to a codon with an ambiguity, gap, or missing data), all characters between the $\mathrm{X}$ and that end of the sequence were deleted and treated as missing data. Each OG was then aligned with MAFFT (mafft -auto -localpair -maxiterate 1000; Katoh (2005)). Alignments were then trimmed with ALISCORE (Misof and Misof, 2009) and ALICUT (Kück, 2009) to remove ambiguously aligned regions. Next, a consensus sequence was inferred for each alignment using the EMBOSS program infoalign (Rice et al., 2000). For each sequence in each single-gene amino acid alignment, the percentage of positions of that sequence that differed from the consensus of the alignment were calculated using infoalign's "change" calculation. Any sequence with a "change" value greater than 75 was deleted. Subsequently, a custom script was used to delete any mistranslated sequence regions of 20 or fewer amino acids in length surrounded by ten or more gaps on either side. This step was important, as sequence ends were occasionally mistranslated or misaligned. Alignment columns with fewer than four non-gap characters were subsequently deleted. At this point, alignments shorter than 75 amino acids in length were discarded. Lastly, we deleted sequences that did not overlap with all other sequences in the 
alignment by at least 20 amino acids, starting with the shortest sequence not meeting this criterion. This step was necessary for downstream single-gene phylogenetic tree reconstruction. As a final filtering step, OGs sampled for fewer than 10 taxa were discarded.

In some cases, a taxon was represented in an OG by two or more sequences (splice variants, lineagespecific gene duplications [=inparalogs], overlooked paralogs, or exogenous contamination). In order to select the best sequence for each taxon and exclude any overlooked paralogs or exogenous contamination, we built trees in FastTree 2 (Price et al., 2010) and used PhyloTreePruner to select the best sequence for each taxon as described above. Remaining OGs were then concatenated using FASconCAT (Kück and Meusemann, 2010). The OGs selected by our bioinformatic pipeline were further screened in seven different ways (subsets listed in Table 2). OGs were first sorted based on amount of missing data; the half with the lowest levels was pulled out as matrix 2 (1699 genes). From matrix 2, a smaller subset of OGs optimized for gene occupancy was extracted, resulting in matrix 3 ( 850 genes). The full supermatrix (matrix 1) was also optimized using the programs MARE (Meyer et al., 2011) and $\mathrm{BaCoCa}$ (Base Composition Calculator; Kück and Struck, 2014). MARE assesses the supermatrix by partition, providing a measure of tree-likeness for each gene and optimizes the supermatrix for information content. The full supermatrix was optimized with an alpha value of 5, to produce matrix 7 (1488 genes, 58 taxa). From the MARE-reduced matrix, genes having no missing partitions for any of the remaining taxa $(n=50)$ were extracted to form a starting matrix for the BEAST analyses (details below). Matrix assessment was also conducted using $\mathrm{BaCoCa}$, which provides a number of descriptive supermatrix statistics for evaluating bias in amino acid composition and patterns in missing data. This program was used to assess for patterns of non-random clusters of sequences in the data, which could potentially mislead phylogenetic analyses. Matrix 4 represents a 50\% reduction of the full supermatrix using $\mathrm{BaCoCa}$ derived values for phylogenetically informative sites as a guide; essentially reducing missing data from absent partitions and gaps. This matrix is similar, but not identical to matrix 2. Matrix 5 resulted from application of arthropod core OGs from Bond et al (2014) to the extended taxon set. Matrix 6 represents the full spider core OG matrix (matrix 1) with Stegodyphus pruned from the tree. OGs for each matrix were concatenated using FASconCAT (Kück and Meusemann, 2010).

\section{Phylogenetics}

Table 2 summarizes run parameters of the seven individual maximum likelihood analyses conducted for each of the supermatrices. We selected the optimal tree for each supermatrix using the computer program ExaML ver. 3.0.1 (Kozlov et al., 2015). Models of amino acid substitution were selected using the AUTOF command in ExaML. Bootstrap data sets and starting parsimony trees for each matrix were generated using RAxML (Stamatakis, 2014) and each individually analyzed in ExaML. We generated 225-300 replicates for each matrix which were then used to construct a majority-rule bootstrap consensus tree; a custom python script was used to automate the process and write a bash script to execute the analyses on a high performance computing (HPC) cluster. The arthropod core OG bootstrap analysis was conducted using RAxML. All analyses were conducted on the Auburn University CASIC HPC and Atrax (Bond Lab, Auburn University).

A coalescent-based method as implemented in ASTRAL (Accurate Species TRee ALgorithm; Mirarab et al., 2014) was used to infer a species tree from a series of unrooted gene trees. The ASTRAL approach is thought to be more robust to incomplete lineage sorting, or deep coalescence, than maximum likelihood analysis of concatenated matrices and works quickly on genome-scale datasets (Mirarab et al., 2014). We first constructed individual gene trees for all partitions contained within matrix 1 . Gene trees were generated using ML based on 100 RAxML random addition sequence replicates followed by 100 bootstrap replicates (Table 2). Subsequent species tree estimation was inferred using ASTRAL v4.7.6, from all individual unrooted gene trees (and bootstrap replicates), under the multi-species coalescent model.

A chronogram was inferred in a Bayesian framework under an uncorrelated lognormal relaxed clock model (Drummond et al., 2006; Drummond and Rambaut, 2007) using Beast v1.8.1 (Drummond et al., 2012). For this analysis we used 43 partitions of a matrix which included complete partitions for all taxa derived from the MARE-optimized matrix 7. The model of protein evolution for each partition was determined using the perl script ProteinModelSelection.pl in RAxML. BEAST analyses were run separately for each partition using eight calibration points based on fossil data. The most recent common ancestor (MRCA) of Mesothelae + all remaining spiders was given a lognormal prior of (mean in real space) $349 \mathrm{Ma}(\mathrm{SD}=0.1)$ based on the Mesothelae fossil Palaeothele montceauensis (Selden, 1996). 
The MRCA of extant araneomorphs was given a lognormal prior of (mean in real space) $267 \mathrm{Ma}$ ( $\mathrm{SD}=0.2$ ) based on the fossil Triassaraneus andersonorum (Selden et al., 1999). The MRCA of extant mygalomorphs was given a lognormal prior of (mean in real space) $278 \mathrm{Ma}(\mathrm{SD}=0.1)$ based on the fossil Rosamygale grauvogeli (Selden and Gall, 1992). The MRCA of Haplogynae + Hypochilidae was given a lognormal prior of (mean in real space) $278 \mathrm{Ma}(\mathrm{SD}=0.1)$ based on the fossil Eoplectreurys gertschi (Selden and Penney, 2010). The MRCA of Deinopoidea (cribellate orb-weavers) was given a lognormal prior of (mean in real space) $195 \mathrm{Ma}(\mathrm{SD}=0.3$ ) based on the fossil Mongolarachne jurassica (Selden et al., 2013). The MRCA of ecribellate orb-weavers was given a lognormal prior of (mean in real space) $168 \mathrm{Ma}(\mathrm{SD}=0.4)$ based on the fossil Mesozygiella dunlopi (Penney and Ortuño, 2006). The MRCA of Nemesiidae, excluding Damarchus, was given a lognormal prior of (mean in real space) $168 \mathrm{Ma}(\mathrm{SD}=0.4)$ based on the nemesiid fossil Cretamygale chasei (Selden, 2002). Finally, the MRCA of Antrodiaetidae was given a lognormal prior of (mean in real space) $168 \mathrm{Ma}(\mathrm{SD}=0.4)$ based on the fossil Cretacattyma raveni (Eskov and Zonstein, 1990). Two or more independent Markov Chain Monte Carlo (MCMC) searches were performed until a parameter effective sample size (ESS) $>200$ was achieved. ESS values were examined in Tracer v1.5. Independent runs for each partition were assembled with LogCombiner v1.7.5 and $10 \%$ percent of generations were discarded as burn-in. Tree files for each partition where then uniformly sampled to obtain 10,000 trees. A total of 430,000 trees (10,000 trees from each partition) were assembled with LogCombiner v1.7.5 and a consensus tree was produced using TreeAnnotator v1.8.1. A chronogram containing all taxa was generated using a penalized likelihood method in r8s v1.8 (Sanderson, 2002). The $95 \%$ highest posterior density dates obtained for the BEAST analysis were incorporated as constraints for node ages of the eight fossil calibrated nodes. The analysis was performed using the TN algorithm, cross validation of branch-length variation and rate variation modeled as a gamma distribution with an alpha shape parameter.

To detect diversification rate shifts, we performed a Bayesian analysis of diversification in BAMM (Bayesian Analysis of Macroevolutionary Mixtures; Rabosky et al., 2014). For this analysis we used the chronogram obtained by the r8s analysis in order to maximize taxon sampling. To account for non-random missing speciation events, we quantified the percentage of taxa sampled per family (World Spider Catalog, 2016) and incorporated these into the analysis. We also accounted for missing families sampled at various taxonomic levels. The MCMC chain was run for 100,000,000 generations, with sampling every 10,000 generations. Convergence diagnostics were examined using coda (Plummer et al., 2006) in R. Ten percent of the runs were discarded as burn-in. The $95 \%$ credible set of shift configurations was plotted in the $\mathrm{R}$ package BAMMtools (Rabosky et al., 2014).

Character state reconstructions of web type following Blackledge et al. (2009) were performed using a maximum likelihood approach. The ML approach was implemented using the rayDISC command in the package corHMM (Beaulieu et al., 2013) in R (Ihaka and Gentleman, 1996). This method allows for multistate characters, unresolved nodes, and ambiguities (polymorphic taxa or missing data). Three models of character evolution were evaluated under the ML method: equal rates (ER), symmetrical (SYM) and all rates different (ARD). A likelihood-ratio test was performed to select among these varying models of character evolution.

\section{RESULTS}

\section{Summary of Genomic Data}

Twenty-one novel spider transcriptomes were sequenced, with an average of 72,487 assembled contigs (contiguous sequences) ranging from 6,816 (Diguetia sp.) to 191,839 (Segestria sp.); specimen data and transcriptome statistics for each sample are summarized in Supplemental Tables S1 and S2 respectively. Median contig length for the novel transcriptomes was $612 \mathrm{bp}$. The complete taxon set, including spider and outgroup transcriptomes from the SRA database, had an average contig number of 53,740 and a range of 5,158 (Paratropis sp.) to 202,311 (Amaurobius ferox) with a median contig length of 655 . The newly constructed spider-specific core ortholog group (OG) set contained 4,934 OGs, more than three times the number of arthropod core orthologs used in prior spider analyses (Bond et al., 2014) and represents a significant step forward in generating a pool of reasonably well-vetted orthologs for spider phylogenomic analyses. The arthropod and spider core orthology sets had 749 groups in common; 4,185 OGs in the spider core were novel. Of the spider-core groups, 4,249 (86\%) were present in the sequenced genome of our HaMSTR reference taxon of choice Acanthoscurria geniculata (Sanggaard et al., 2014) and were retained for use in downstream ortholog detection. The number of TransDecoder predicted proteins and 
ortholog detection success for each taxon is summarized in Table S2. Annotations for the arthropod set can be found in Bond et al. (2014); Supplemental Table S3 summarizes gene annotations for the spider core ortholog set generated for this study. Our new HaMStR spider core ortholog set and Acanthoscurria geniculata BLAST database file can be downloaded from the Dryad Data Repository at doi.xxxx.xxxxxx.

\section{Phylogenetic Analyses}

Seven super matrices were generated for downstream non time-calibrated analyses (Figure 2), one drawn from the arthropod core set and six using the spider core set. Data set sizes, summarized in Table 2, ranged from a maximum of 3,398 OGs with a higher percentage of missing cells (38.5\%), 850 OGs with $19.6 \%$ missing, to 549 OGs (arthropod core set) with 33\% missing data. Two matrices were generated using automated filtering approaches implemented by $\mathrm{BaCoCa}$ (Kück and Struck, 2014) and MARE (Meyer et al., 2011). In $\mathrm{BaCoCa}$ we sorted partitions using number of informative sites, capturing the top half ( 1700 OGs) of the matrix containing the most informative sites. RCFV values generated by $\mathrm{BaCoCa}$ were $<0.05$ for all taxa in all partitions for each of the matrices, indicating homogeneity in base composition. Additionally, there was no perceptible taxonomic bias observed in shared missing data (Supplemental Figures S1-S6). The MARE optimized matrix comprised 58 taxa and 1,488 genes with $19.6 \%$ missing data. For graphical representations of gene occupancy for each matrix, see Supplemental Figures S7-S12. Blast2GO (Conesa et al., 2005) gene ontology distributions of molecular function for OGs recovered from both the spider and arthropod ortholog sets (Supplemental Figures S13 and S14) can be found in the supplemental materials.

Our phylogenetic analyses (see Table 2 and Discussion), the results of which are summarized in Figure 2, consistently recover many well-supported monophyletic groups: Araneae, Mygalomorphae, Araneomorphae, Synspermiata (i.e., Haplogynae excluding Filistatidae and Leptonetidae), Entelegynae, the RTA clade, Dionycha, and Lycosoidea. Within Mygalomorphae, Atypoidina and Avicularioidea are monophyletic; Nemesiidae is polyphyletic. Filistatidae (Kukulcania) emerges as the sister group to Hypochilus. Interestingly, Leptonetidae emerges as the sister group to Entelegynae. Eresidae is sister to Araneoidea, similar to findings of Miller et al. (2010). Deinopoidea is polyphyletic. Oecobiidae is sister to Uloboridae, which are together sister to Deinopidae plus the RTA clade. Homalonychidae and by implication the entire Zodarioidea (Miller et al., 2010), is sister to Dionycha plus Lycosoidea. Hahniidae, represented by the cryphoecine Calymmaria, is sister to Dictynidae. Thomisidae belongs in Lycosoidea as proposed by Homann (1971) and Polotow et al. (2015) (see also Ramírez, 2014).

Coalescent-based species-tree analysis in ASTRAL employed unrooted gene trees based on the 3,398 gene matrix as input and inferred a well-supported tree (most nodes $>95 \%$ bs; Figure 3). With few exceptions the topology recovered using this approach was congruent with the likelihood-based supermatrix analysis. Conflicting nodes, some corresponding to key araneomorph lineages, which were moderately to weakly supported in concatenated analyses, are summarized in Figure 2.

A chronogram based on 43 partitions with no missing data (matrix 7, see Table 2) is shown in Figure 4. MRCA Divergence time estimates are summarized in Table 3: Mesothelae - Opisthothelae at $340 \mathrm{Ma}$ (287-398 95\% CI); Mygalomorphae - Araneomorphae at $308 \mathrm{Ma}$ (258-365 95\% CI); Synspermiata + Hypochilidae - Entelegynae at $276 \mathrm{Ma}$ (223-330 95\% CI); RTA + Deinopoidea - Stegodyphus + Araneoidea at $214 \mathrm{Ma}(154-280$ 95\% CI); RTA - Dionycha at $138.8 \mathrm{Ma}$ (Figure 4).

Diversification rate shift analysis estimated three instances of significant diversification shifts within spiders (95\% credibility). The highest rate shift is within the RTA + Dionycha + Lycosoidea (Figure 5) followed by Avicularioidea and within Araneoidea ( $f=0.23 ; 0.21$; Figure 5).

Maximum likelihood ancestral state reconstruction of web type (Figure 6) shows that the spider common ancestor likely foraged from a subterranean burrow, sometimes sealed by a trapdoor. The ancestral condition for araneomorphs may have been a stereotypical aerial sheet. Entelegynae ancestors probably spun orbs, which were subsequently lost at least three times. RTA taxa largely abandoned webs to become hunting spiders. Precise location of these character state shifts depends upon sufficient sampling; denser sampling reduces the number of unobserved evolutionary events. While this analysis contains only 47 of 114 spider families, the sequence and overall mapping to the spider backbone phylogeny is strongly supported. 


\section{DISCUSSION}

Our phylogenomic analyses represent the largest assessment of spider phylogeny to date using genomic data, both in terms of taxa and number of orthologs sampled. Our results are largely congruent with earlier work (Bond et al., 2014): we recover all of the major backbone lineages (Mygalomorphae, Araneomorphae, RTA, etc.), but reiterate that our understanding of spider evolutionary pattern and process needs thorough reconsideration. This expanded study reinforces the ancient origin of the orb web hypothesis (Bond et al., 2014) and shows that rates of spider species diversification appear to be associated with web change or loss - or with modification of the male palp rather than the origin of the orb web. It shows that the Haplogynae are polyphyletic with Filistatidae as sister to Hypochilidae and Leptonetidae as sister to Entelegynae. It also suggests a position for two enigmatic families - Hahniidae and Homalonychidae and provides an alternate view of RTA relationships and the contents of Dionycha clade.

\section{Data Characteristics and Development of Spider Core Orthologs}

Transcriptome analyses are unquestionably data rich. Thousands of assembled sequences emerge from even modest RNA-seq experiments, providing, among other things, a basis for identifying phylogenetically informative orthologs. This bounty comes with a few caveats. Isoforms, paralogous sequences, and assembly artifacts (chimeric contigs) can mislead inference of single-copy orthologous genes. The data represent one snapshot - a specific organism, point in time, and combination of tissues - that can lead to gaps in downstream supermatrices due to stochastic sampling issues. Large amounts of missing data, due to missing loci and indels introduced during alignment, can arise post-assembly in the ortholog detection and filtering stages of phylogenomic analyses (Bond et al., 2014; Fernández et al., 2014). Lemmon et al. (2009) and a number of other authors (Roure et al., 2013; Dell'Ampio et al., 2014; Xia, 2014) have discussed the potential negative effects of such missing data in large phylogenomic (transcriptomebased) datasets. Recent studies argue that the phylogenetic signal from transcriptomes can conflict with alternative reduced representation approaches like targeted sequence capture (Jarvis et al., 2014; Brandley et al., 2015; Prum et al., 2015). From vast amounts of bird genome protein-coding data, Jarvis et al. (2014) concluded that these loci were not only insufficient (low support values), but also misleading due to convergence and high levels of incomplete lineage sorting during rapid radiations.

Simulation studies now predict that 10's-100's of loci will resolve most phylogenies, albeit sensitive to factors such as population size or speciation tempos (Knowles and Kubatko, 2011; Leache and Rannala, 2011; Liu and Yu, 2011). To mitigate the impacts of paralogy, incomplete lineage sorting, and missing data, we developed a priori a set of spider core orthologs that comprise a database consisting of over 4,500 genes that are expected to be recovered from most whole spider RNA extractions and are likely orthologous. We summarize the annotations for each of the genes in the HaMStR pHMM file in Supplemental table S3.

Our approach enhances repeatability, downstream assessment, scalability (taxon addition), and data quality. Studies that employ pure clustering approaches like OMA stand-alone (Altenhoff et al., 2013) may produce more data (i.e., more "genes") on the front end; however, they present some problems in terms of ease of scalability. Although adding more genes is one strategy, it is increasingly clear that taxon sampling and data quality are very important (Lemmon and Lemmon, 2013; Bond et al., 2014).

\section{A Modified View of Spider Evolution and Key Innovations}

Once considered the "crowning achievement of aerial spiders" (Gertsch, 1979), the orb web and consequent adaptive radiation of araneoid spiders (ecribellate orb weavers and their relatives) captured the imagination of spider researchers for over a century. The evolution of adhesive threads and the vertical orientation of the orb web, positioned to intercept and retain flying insects, has been long considered a "key innovation" that allowed spiders to inhabit a new adaptive zone (Bond and Opell, 1998). It is important to note that several prior authors speculated about orb web adaptive value, such as Levi (1980), Opell $(1979,1983)$, and Coddington (1986), although Bond and Opell (1998) quantified the pattern in a formal phylogenetic framework. Over $25 \%$ of all spider species are araneoids. Given orb weaver monophyly on quantitative phylogenies (Griswold et al., 1998; Blackledge et al., 2009), rigorous empirical studies tended to confirm the orb as a prime cause of spider diversification (Bond and Opell, 1998). Nevertheless, a lack of correlation of the orb web and species richness has been apparent for some time. Griswold et al. (1998) noted that over 50\% of Araneoidea no longer build recognizable orb webs and suggested that "the orb web has been an evolutionary base camp rather than a summit." 
Bond et al. (2014) tested two alternative evolutionary scenarios for orb web evolution, reflecting different analytical results; parsimony implied multiple independent origins, and maximum likelihood implied one origin and subsequent multiple losses. The current study (Figure 6) favors the latter: the orb evolves at the base of the araneoid + deinopoid + RTA clade, but is lost at least three times independently. Large amounts of morphological and behavioral data (albeit often correlated with features essential to the orb) still support the single origin hypothesis (Coddington, 1986, 1991; Scharff and Coddington, 1997; Griswold et al., 1998; Agnarsson et al., 2013). Our results suggest both that the orb web originated earlier than previously supposed, and that heretofore-unsuspected clades of spiders descend from orb weavers. In a sense, this ancient origin hypothesis reconciles the implications of genomic data with the classical evidence for multiple, homologous, complex, co-adapted character systems.

Recent discoveries of large, cribellate orb web-weaving taxa from the late Triassic agree with our molecular dates. Diverse Mesozoic deinopoids (Selden et al., 2015) are consistent with the "orb web node" at $213 \mathrm{Ma}$ (Figure 4, Table 3). Under this view, modern uloborids and deinopids are distinct remnants of this diverse group. Selden et al. (2015) previously noted that if other extant taxa "emerged from the deinopoid stem or crown group it would render the whole-group Deinopoidea paraphyletic"; we discuss this scenario in detail below.

Contrary to the contemporary paradigm that the evolution of the orb web and adhesive sticky threads elevated rates of diversification among the araneoid spiders, our BAMM analysis (Figure 5) indicates that the highest rates of diversification likely occurred among the RTA spiders followed by mygalomorphs and then araneoids as a distant third, the latter driven-in part-by the secondarily non-orb weaving theridiids and linyphiids. These results imply that other foraging strategies (e.g. cursorial hunting and irregular sheets) were a more "successful" strategy than the orb. Indeed, the point estimate for the RTA node during the early Cretaceous (138.8 Ma; Figure 4, Table 3) precedes the subsequent diversification of the RTA clade at $125-100 \mathrm{Ma}$.

This date coincides with the Cretaceous Terrestrial Revolution (KTR). Angiosperms radiated extensively at 125-90 Ma (Crane, 1987; Wang et al., 2013), as did various plant-dependent insect lineages, including beetles (McKenna et al., 2009; Mckenna et al., 2015), lepidopterans (Wahlberg et al., 2013), ants (Moreau, 2006), and holometabolous insects in general (Misof et al., 2014), although some insect lineages do not show a pulse (e.g., darkling beetles; Kergoat et al., 2014). Spiders, as important insect predators, may also have diversified rapidly along with their prey (e.g., Penney et al., 2003; Penalver, 2006; Selden and Penney, 2010). The fossil and phylogenomic data presented here show that most spider lineages predate the KTR (Selden and Penney, 2010; Bond et al., 2014). Among these, the RTA clade especially, but also mygalomorphs and araneoids, diversified in response to the KTR insect pulse. That aerial web spinners specialized on rapidly radiating clades of flying insects is hardly surprising. Similarly, if forest litter habitats became more complex and spurred insect diversification (Moreau, 2006), ground-dwelling spiders may also have diversified at unusual rates. Perhaps the most dramatic change in insect abundances occurred with the origin and early diversification of social insects that today dominate animal biomass on the planet (Hölldobler and Wilson, 1990) and beetles (Mckenna et al., 2015). Both groups date back to 150-125 my and diversified during the KTR (LaPolla et al., 2013; Ward, 2014; Legendre et al., 2015). A major increase in these insect groups may have favoured spiders that feed on cursorial prey and thus could help explain the concurrent increase in diversification in the RTA clade, mygalomorphs, and non-orb weaving araneoids such as cobweb weavers (Dziki et al., 2015).

Taken together, this new evidence on character evolution, divergence estimates, and rates of diversification indicates that previous conclusions regarding the timing and rate of spider evolution were imprecise, if not faulty. Our data support an ancient orb web hypothesis that is further bolstered by a wealth of fossil data showing that a cribellate deinopoid stem group likely diversified during the early Mesozoic. Molecular divergence clock estimates are consistent with the placement of the orb web further down the tree as well as suggesting that some of the greatest rates of species diversification coincided with the KTR. The latter suggests that spiders took advantage of increased abundance of cursorial prey.

These findings likely diminish the hypothesis proposed by Bond and Opell (1998) that the vertically oriented orb web represented a key innovation, particularly in light of the fact that over half of araneoid species do not build an orb web (e.g. Theridiidae and Linyphiidae; noted by Griswold et al., 1998; Fernández et al., 2014). We already knew that major orb web-weaving groups are very successful in spite of abandoning the orb (Blackledge et al., 2009). 


\section{Spider Systematics}

Although our results show that many classical ideas in spider systematics require revision (e.g. mygalomorph families, Haplogynae, paleocribellates, higher araneoids, and RTA + dionychan lineages), they also robustly support many classical taxonomic concepts.

\section{Mygalomorphae relationships.}

Since Raven (1985), Mygalomorphae (Table 1, Node 4) has continuously represented a challenge to spider systematics. As discussed by Hedin and Bond (2006) and Bond et al. (2012), nearly half the families are probably non-monophyletic. While our sampling here and previously (Bond et al., 2014) is far greater than any other published phylogenomic study (e.g., Fernández et al. (2014) included just one theraphosid), taxon sampling remains insufficient to address major issues aside from deeper level phylogenetic problems. However, the data (Figure 2) support Euctenizidae as a monophyletic family, but not Nemesiidae. As indicated in Bond et al. (2014), the once controversial Atypoidina (Node 5) consistently has strong statistical support in all analyses. Alternatively, the placement of paratropidids, ctenizids, and idiopids remains questionable and warrants further sampling.

\section{Haplogynae relationships.}

The traditional view of spider classification (Coddington, 2005) places Paleocribellatae and Austrochiloidea (Table 1) as sister groups to all the remaining Araneomorphae taxa - Haplogynae and Entelegynae; the latter terms are used primarily herein as clade names rather than specific reference to genitalic condition. Our current tree (Figure 2) is congruent with Bond et al. (2014) in placing Paleocribellatae (Table 1, Hypochilus; Figure 1, Node 9) as sister to Haplogynae. Filistatidae (Kukulcania), which is placed as sister to the ecribellate haplogynes (Synspermiata lineage as proposed in Michalik and Ramírez, 2014), pairs with Hypochilus as in Bond et al. (2014). This arrangement suggests that characters formerly considered "primitive" to araneomorphs, for example, mobile leg three cribellate silk carding, might instead be a synapomorphy for the new hypochilid-filistatid clade. Remaining haplogyne relationships are somewhat congruent with previously published analyses (Ramírez, 2000; Michalik and Ramírez, 2014). However, one of the more intriguing results is the placement of the morphologically intermediate "haplogyne" (Table 1) Calileptoneta (Leptonetidae) as sister to Entelegynae, suggesting that leptonetids may represent intermediate genitalic forms between haplogyne and the relatively more complex entelegyne condition (Ledford and Griswold, 2010). As outlined by Ledford and Griswold (2010), a number of previous analyses (Platnick et al., 1991; Ramírez, 2000; Griswold et al., 2005) discussed the "rampant" homoplasy required to place leptonetids (sister to Telemidae) among haplogynes and suggest two possible scenarios - leptonetids are proto-entelegynes, or they are the sister group to the remaining Haplogynae. Our phylogenomic analyses support the former hypothesis favored by Ledford and Griswold (2010), and puts the discovery of the cribellate Archoleptoneta into better phylogenetic context. Additionally, these results provide further support for the concept of Synspermiata as proposed by Michalik and Ramírez (2014) and represent a robust phylogenetic framework for understanding the evolution of entelegyne genitalia.

\section{Araneoidea relationships.}

Our reconstruction of araneoid relationships departs dramatically from the traditional classification scheme and a number of recently published molecular systematic studies (e.g., Blackledge et al., 2009; Dimitrov et al., 2012). Theridiidae (cobweb spiders) is sister to the remaining araneoids as opposed to occupying a more derived position within that clade. Comparisons to Dimitrov et al. (2012) should be viewed with caution: that analysis had a large suite of taxa not included here, and many results of that analysis had only weak support. Nevertheless, our phylogenomic data agree in supporting the close relationship between Mysmenidae, Mimetidae, and Tetragnathidae. We also retain the more inclusive linyphioids as close relatives of Araneidae + Nephilidae as in Dimitrov et al. (2012). Unlike that study, we recover nesticids sister to linyphioids (Pimoidae plus Linyphiidae) rather than theridiids: Theridioid (Theridiidae and Nesticidae) diphyly is a surprising result, which has already been shown with standard markers by Agnarsson et al. (2013). Theridioids have strikingly similar spinning organs and tarsus IV comb for throwing silk, but are otherwise genitalically distinct. Clearly relationships among the derived araneoids require more intensive sampling, especially of missing families (Theridiosomatidae, Malkaridae, Anapidae, etc.) to adequately resolve their phylogeny. 


\section{Deinopoidea relationships.}

The addition of nearly 30 terminals to the Bond et al. (2014) dataset corroborates the non-monophyly of the classically defined Orbiculariae, although the orb and its behavioral, morphological, and structural constituents may be homologous. Deinopoidea, with these data, is polyphyletic (see also Dimitrov et al., 2012). Instead, a new clade, Uloboridae + Oecobiidae, is sister to Deinopidae + the RTA clade. Bootstrap support was consistently low for the node dividing these two groupings in all analyses except matrix 6 (Figure 2), which omits the eresid exemplar Stegodyphus and matrix 8, the ASTRAL analysis. The placement of the two eresoid taxa (Table 1), Stegodyphus and Oecobius continues to present difficulties here as in previous published phylogenomic studies (Miller et al., 2010). Fernández et al. (2014) found alternative placements for Oecobius (their only eresoid) whereas Bond et al. (2014) typically recovered Stegodyphus as the sister group to all entelegynes (recovered here as the sister group to araneoids) and Oecobius as a member of a clade comprising uloborid and deinopid exemplars, but with notably lower support. Disparities between the two analyses may be attributed to differences in taxon sampling, which, as noted above, was far greater in Bond et al. (2014). On the other hand, increased taxon sampling across the tree diminished node support in some places. However, it is worth noting that support was very strong in the ASTRAL species tree analysis, suggesting that while there may be some conflict among individual data partitions there is an overwhelming amount of signal in the data for a Deinopoidea + RTA relationship. This trend was noted by Bond et al. (2014) who found that only $2.4 \%$ of all bootstrap replicates recovered a monophyletic Orbiculariae. Based on these data and the putative rapid diversification that occurred once the orb web was abandoned, it is clear that resolving relationships at this point in spider evolutionary history remains a challenge. Finally, Bond et al. (2014) and Agnarsson et al. (2013) recovered an unexpected relationship between eresoid taxa and deinopoids that consistently rendered the Deinopoidea paraphyletic or polyphyletic if Oecobius was included in the analysis. Our results, here including an additional uloborid exemplar, still confirm Deinopoidea polyphyly. Perhaps careful examination of Oecobius web morphology and spinning behavior will provide independent corroboration of this molecular signal.

\section{RTA and Dionycha relationships.}

Although all of our analyses recover a monophyletic RTA clade, relationships among its members reflect some departure from the traditional view of RTA phylogeny but are largely consistent with a more recent morphology-based study. We recover a clade that comprises a mix of agelenoids (Agelenidae, Desidae, and Amphinectidae) as a sister group to Dictynidae + Hahniidae and Amaurobiidae. The taxonomic composition of Dictynidae, Hahniidae and Amaurobiidae, as well as their phylogenetic placement, remains problematic and in a state of flux (Coddington, 2005; Spagna et al., 2010; Miller et al., 2010). The typical hahniine hahniids have been difficult to place due to their long branches (Spagna and Gillespie, 2008; Miller et al., 2010). Calymmaria, has been moved into "Cybaeidae s.l." by Spagna et al. (2010), suggesting that the relationships among hahniids, cybaeids, and dictynids need further scrutiny.

Amaurobiids have also been hard to place, though this is in part because Amaurobiidae are a moving target. The term "Amaurobiids" needs to be clarified, as most of nine subfamilies discussed in Lehtinen (1967) are now placed elsewhere. We use Callobius, from the type subfamily of the family. Our amaurobiid placement, basal to an agelenoid and dictynoid grouping corroborates previous findings (Miller et al., 2010; Spagna et al., 2010). Dictynids on the other hand were considered one of the unresolved sister groups to amaurobioids, zodarioids, and dionychans (Spagna et al., 2010). Here the placement of our dictynid exemplar Cicurina is more precise: sister group to the hahniid Calymmaria (as in Miller et al., 2010).

We also recover Homalonychidae (representing Zodarioidea) as the sister group to dionychans and lycosoids, once again, mirroring the results of Agnarsson et al. (2013). Previously Zodarioidea was placed closer to the base of the RTA clade (Miller et al., 2010). Dionychans here include salticids, anyphaenids, corinnids, and gnaphosids whereas crab spiders (Thomisidae) nest with the lycosoids containing a paraphyletic Pisauridae. Placement of Thomisidae within Lycosoidea goes back at least to Homann (1971) and was formally established by Bayer and Schönhofer (2013) and the total evidence analysis of Polotow et al. (2015). Although Ramírez (2014) placed Thomisidae outside of Lycosoidea, in one of his slightly suboptimal results thomisids were included in Lycosoidea. The relationships we recover among dionychan and lycosoid taxa are largely congruent with those inferred by Ramírez (2014) in a massive morphological study of Dionycha and RTA exemplars. Given the general incongruence among previous morphological and molecular spider systematic studies, it will be interesting to see how 
Ramírez (2014) phylogeny and familial-level reevaluations compare as phylogenomic studies expand. Raven (1985) was a landmark study for mygalomorphs; perhaps Ramírez (2014) may serve in the same capacity for one of the most diverse branches on the spider tree of life.

\section{CONCLUSIONS}

Following Coddington and Levi (1991), higher-level spider classification underwent a series of challenges from quantitative studies of morphology, producing provocative but weakly-supported hypotheses (Griswold et al., 1998, 2005). Total evidence studies, for example, Wood et al. (2012a,b) for Palpimanoidea, Polotow et al. (2015) for Lycosoidea, and Bond et al. (2012) for Mygalomorphae appear to have settled some local arrangements, but much of the backbone of the spider tree of life remains an open question only to be solved through increased taxon sampling. Phylogenomics has already brought data-rich, convincing solutions to long standing controversies, for example, phylogeny of the orb web (Bond et al., 2014; Fernández et al., 2014). Phylogenomics portends a new and exciting period for spider evolutionary biology. Recent advances in digital imaging, proteomics, silk biology and major fossil discoveries mean that our understanding of spider evolution will likely accelerate by leaps and bounds in the coming years. The tempo and mode of spider evolution is likely different than previously thought. At this point it seems reasonably clear that the orb web evolved earlier phylogenetically than previously thought, only to be subsequently lost at least three times independently during the Cretaceous. While the orb web has certainly been successful, a likely dramatic increase in the abundances of cursorial insects during the KTR, also impacted the success of other foraging strategies, including webless hunting. Our results and that of others like Ramírez (2014) show that spider systematics still remains a work in progress with many questions remaining to be answered.

\section{ADDITIONAL INFORMATION AND DECLARATIONS}

\section{Acknowledgments}

This is contribution 7XX of the Auburn University Museum of Natural History. The authors would like to thank an anonymous reviewer, S. Edwards, F. Labarque, P. Michalik, J. Miller, M.J. Ramirez, and R. Raven for insightful comments on earlier drafts of this manuscript.

\section{Accession Numbers}

Illumina transcriptome sequence data are available from NCBI database archive under accession numbers SAMNXXXXX-SAMNXXXXX. Phylogenomics data matrices were deposited on XX November 2015 in the Dryad Digital Repository at http://dx.doi.org/xx.xxxx/drayd.xxxxx.

\section{Supplemental Information}

Supplemental information, figures and tables, can be found online at http://dx.doi.org/xx.xxxx/peerj.

\section{REFERENCES}

Agnarsson, I., Coddington, J. A., and Kuntner, M. (2013). Systematics - progress in the study of spider diversity and evolution. In Penney, D., editor, Spider Research in the 21st Century, pages 58-111. Manchester.

Altenhoff, A. M., Gil, M., Gonnet, G. H., and Dessimoz, C. (2013). Inferring Hierarchical Orthologous Groups from Orthologous Gene Pairs. PLoS ONE, 8(1):e53786.

Altschul, Stephen F., Gish, Warren, Miller, Webb, Myers, Eugene W., and Lipman, David J. (1990). Basic Local Alignment Search Tool. Journal of Molecular Biology, 215:403-410.

Bayer, S. and Schönhofer, A. L. (2013). Phylogenetic relationships of the spider family psechridae inferred from molecular data, with comments on the lycosoidea (arachnida: Araneae). Invertebrate systematics, 27(1):53-80.

Beaulieu, J. M., O’Meara, B. C., and Donoghue, M. J. (2013). Identifying Hidden Rate Changes in the Evolution of a Binary Morphological Character: The Evolution of Plant Habit in Campanulid Angiosperms. Systematic Biology, 62(5):725-737.

Blackledge, T. A., Kuntner, M., and Agnarsson, I. (2011). The form and function of spider orb webs: evolution from silk to ecosystems. Advances in Insect Physiology, 41:175. 
Blackledge, T. A., Scharff, N., Coddington, J. A., Szüts, T., Wenzel, J. W., Hayashi, C. Y., and Agnarsson, I. (2009). Reconstructing web evolution and spider diversification in the molecular era. Proceedings of the National Academy of Sciences of the United States of America, 106(13):5229-5234.

Bond, J. E., Garrison, N. L., Hamilton, C. A., Godwin, R. L., Hedin, M., and Agnarsson, I. (2014). Phylogenomics Resolves a Spider Backbone Phylogeny and Rejects a Prevailing Paradigm for Orb Web Evolution. Current Biology, 24(15):1765-1771.

Bond, J. E., Hendrixson, B. E., Hamilton, C. A., and Hedin, M. (2012). A Reconsideration of the Classification of the Spider Infraorder Mygalomorphae (Arachnida: Araneae) Based on Three Nuclear Genes and Morphology. PLOS ONE, 7(6):e38753.

Bond, J. E. and Opell, B. D. (1998). Testing Adaptive Radiation and Key Innovation Hypotheses in Spiders. Evolution, 52(2):403.

Brandley, M. C., Bragg, J. G., Singhal, S., Chapple, D. G., Jennings, C. K., Lemmon, A. R., Lemmon, E. M., Thompson, M. B., and Moritz, C. (2015). Evaluating the performance of anchored hybrid enrichment at the tips of the tree of life: a phylogenetic analysis of Australian Eugongylus group scincid lizards. BMC Evolutionary Biology, 15(62).

Coddington, J. (1986). The monophyletic origin of the orb web. In Shear, W., editor, Spiders: Webs, Behavior, and Evolution, pages 319-363. Stanford University Press, Stanford, California.

Coddington, J. A. (1991). Cladistics and spider classification: araneomorph phylogeny and the monophyly of orbweavers (Araneae: Araneomorphae; Orbiculariae). Acta Zoologica Fennica, 190:75-87.

Coddington, J. A. (2005). Phylogeny and classification of spiders. In Ubick, P., Paquin, P., Cushing, P., and Roth, V., editors, Spiders of North America: an identification manual, pages 18-24. American Arachnological Society.

Coddington, J. A. and Levi, H. W. (1991). Systematics and Evolution of Spiders (Araneae). Annual Review of Ecology and Systematics, 22:565-592.

Conesa, A., Götz, S., García-Gómez, J. M., Terol, J., Talón, M., and Robles, M. (2005). Blast2go: a universal tool for annotation, visualization and analysis in functional genomics research. Bioinformatics, 21(18):3674-3676.

Crane, P. (1987). The origin of angiosperms and their biological consequences. In Friis, E., Chaloner, W., and Crane, P., editors, Vegetational consequences of the angiosperm diversification, pages 105-144. Cambridge University Press, Cambridge.

Dell'Ampio, E., Meusemann, K., Szucsich, N. U., Peters, R. S., Meyer, B., Borner, J., Petersen, M., Aberer, A. J., Stamatakis, A., Walzl, M. G., Minh, B. Q., von Haeseler, A., Ebersberger, I., Pass, G., and Misof, B. (2014). Decisive Data Sets in Phylogenomics: Lessons from Studies on the Phylogenetic Relationships of Primarily Wingless Insects. Molecular Biology and Evolution, 31(1):239-249.

Dicko, C., Porter, D., Bond, J., Kenney, J. M., and Vollrath, F. (2008). Structural Disorder in Silk Proteins Reveals the Emergence of Elastomericity. Biomacromolecules, 9(1):216-221.

Dimitrov, D., Lopardo, L., Giribet, G., Arnedo, M. A., Alvarez-Padilla, F., and Hormiga, G. (2012). Tangled in a sparse spider web: single origin of orb weavers and their spinning work unravelled by denser taxonomic sampling. Proceedings of the Royal Society B: Biological Sciences, 279(1732):13411350.

Drummond, A. J., Ho, S. Y. W., Phillips, M. J., and Rambaut, A. (2006). Relaxed Phylogenetics and Dating with Confidence. PLoS Biology, 4(5):e88.

Drummond, A. J. and Rambaut, A. (2007). BEAST: Bayesian evolutionary analysis by sampling trees. BMC Evolutionary Biology, 7(1):214.

Drummond, A. J., Suchard, M. A., Xie, D., and Rambaut, A. (2012). Bayesian phylogenetics with BEAUti and the BEAST 1.7. Molecular biology and evolution, 29(8):1969-1973.

Dziki, A., Binford, G., Coddington, J. A., and Agnarsson, I. (2015). Spintharus flavidus in the caribbean-a 30 million year biogeographical history and radiation of a 'widespread species'. Technical report, PeerJ PrePrints.

Ebersberger, I., Strauss, S., and von Haeseler, A. (2009). HaMStR: Profile hidden markov model based search for orthologs in ESTs. BMC Evolutionary Biology, 9(1):157.

Eddy, S. R. (2011). Accelerated Profile HMM Searches. PLoS Computational Biology, 7(10):e1002195. Eskov, K. Y. and Zonstein, S. (1990). First Mesozoic mygalomorph spiders from the Lower Cretaceous of Siberia and Mongolia, with notes on the system and evolution of the infraorder Mygalomorphae (Chelicerata: Araneae). Neues Jahrbuch für Geologie und Paläontologie, Abhandlungen, 178:325-368. 
Fernández, R., Hormiga, G., and Giribet, G. (2014). Phylogenomic Analysis of Spiders Reveals Nonmonophyly of Orb Weavers. Current Biology, 24(15):1772-1777.

Garb, J. and Penney, D. (2013). Spider silk: An ancient biomaterial for the 21st century. Spider Research in the 21st Century: Trends and Perspectives.(D. Penney, ed.). Siri Scientific Press, Manchester, UK, pages 252-281.

Gertsch, W. J. (1979). American spiders. Number Ed. 2. Van Nostrand Reinhold Co.

Grabherr, M. G., Haas, B. J., Yassour, M., Levin, J. Z., Thompson, D. A., Amit, I., Adiconis, X., Fan, L., Raychowdhury, R., Zeng, Q., Chen, Z., Mauceli, E., Hacohen, N., Gnirke, A., Rhind, N., di Palma, F., Birren, B. W., Nusbaum, C., Lindblad-Toh, K., Friedman, N., and Regev, A. (2011). Full-length transcriptome assembly from RNA-Seq data without a reference genome. Nature Biotechnology, 29(7):644-652.

Griswold, C. E., Coddington, J. A., Hormiga, G., and Scharff, N. (1998). Phylogeny of the orb-web building spiders (Araneae, Orbiculariae: Deinopoidea, Araneoidea). Zoological Journal of the Linnean Society, 123(1):1-99.

Griswold, C. E., Ramírez, M., Coddington, J., and Platnick, N. (2005). Atlas of Phylogenetic Data for Entelegyne Spiders (Araneae: Araneomorphae: Entelegynae), with Comments on Their Phylogeny. Procceedings of the California Academy of Sciences, 56:1-324.

Haas, B. J., Papanicolaou, A., Yassour, M., Grabherr, M., Blood, P. D., Bowden, J., Couger, M. B., Eccles, D., Li, B., Lieber, M., MacManes, M. D., Ott, M., Orvis, J., Pochet, N., Strozzi, F., Weeks, N., Westerman, R., William, T., Dewey, C. N., Henschel, R., LeDuc, R. D., Friedman, N., and Regev, A. (2013). De novo transcript sequence reconstruction from RNA-seq using the Trinity platform for reference generation and analysis. Nature Protocols, 8(8):1494-1512.

Hedin, M. and Bond, J. E. (2006). Molecular phylogenetics of the spider infraorder Mygalomorphae using nuclear rRNA genes (18s and 28s): Conflict and agreement with the current system of classification. Molecular Phylogenetics and Evolution, 41(2):454-471.

Homann, H. (1971). Die Augen der Araneae. Zeitschrift für Morphologie der Tiere, 69(3):201-272.

Hormiga, G. and Griswold, C. E. (2014). Systematics, Phylogeny, and Evolution of Orb-Weaving Spiders. Annual Review of Entomology, 59(1):487-512.

Hölldobler, B. and Wilson, E. O. (1990). The ants. Harvard University Press.

Ihaka, R. and Gentleman, R. (1996). R: A Language for Data Analysis and Graphics. Journal of Computational and Graphical Statistics, 5(3):299.

Jarvis, E. D., Mirarab, S., Aberer, A. J., Li, B., Houde, P., Li, C., Ho, S. Y., Faircloth, B. C., Nabholz, B., Howard, J. T., and others (2014). Whole-genome analyses resolve early branches in the tree of life of modern birds. Science, 346(6215):1320-1331.

Katoh, K. (2005). MAFFT version 5: improvement in accuracy of multiple sequence alignment. Nucleic Acids Research, 33(2):511-518.

Kergoat, G. J., Soldati, L., Anne-Laure Clamens, Jourdan, H., Jabbour-Zahab, R., Genson, G., Bouchard, P., and Condamine, F. L. (2014). Higher level molecular phylogeny of darkling beetles (Coleoptera: Tenebrionidae): Darkling beetle phylogeny. Systematic Entomology, 39(3):486-499.

King, G. F. and Hardy, M. C. (2013). Spider-Venom Peptides: Structure, Pharmacology, and Potential for Control of Insect Pests. Annual Review of Entomology, 58(1):475-496.

Knowles, L. L. and Kubatko, L. S. (2011). Estimating species trees: practical and theoretical aspects. John Wiley and Sons.

Kocot, Moroz, L., Citarella, M., and Halanych, K. (2013). PhyloTreePruner: A Phylogenetic Tree-Based Approach for Selection of Orthologous Sequences for Phylogenomics. Evolutionary Bioinformatics, page 429.

Kocot, K. M., Cannon, J. T., Todt, C., Citarella, M. R., Kohn, A. B., Meyer, A., Santos, S. R., Schander, C., Moroz, L. L., Lieb, B., and Halanych, K. M. (2011). Phylogenomics reveals deep molluscan relationships. Nature, 477(7365):452-456.

Kozlov, A. M., Aberer, A. J., and Stamatakis, A. (2015). ExaML version 3: a tool for phylogenomic analyses on supercomputers. Bioinformatics, 31(15):2577-2579.

Kück, P. (2009). ALICUT: a Perlscript which cuts ALISCORE identified RSS. Department of Bioinformatics, Zoologisches Forschungsmuseum A. Koenig (ZFMK), Bonn, Germany, version, 2.

Kück, P. and Meusemann, K. (2010). FASconCAT: Convenient handling of data matrices. Molecular Phylogenetics and Evolution, 56(3):1115-1118. 
Kück, P. and Struck, T. H. (2014). BaCoCa - A heuristic software tool for the parallel assessment of sequence biases in hundreds of gene and taxon partitions. Molecular Phylogenetics and Evolution, 70:94-98.

LaPolla, J. S., Dlussky, G. M., and Perrichot, V. (2013). Ants and the Fossil Record. Annual Review of Entomology, 58(1):609-630.

Leache, A. D. and Rannala, B. (2011). The Accuracy of Species Tree Estimation under Simulation: A Comparison of Methods. Systematic Biology, 60(2):126-137.

Ledford, J. M. and Griswold, C. E. (2010). A study of the subfamily Archoleptonetinae (Araneae, Leptonetidae) with a review of the morphology and relationships for the Leptonetidae. Zootaxa, 2391:1-32.

Legendre, F., Nel, A., Svenson, G. J., Robillard, T., Pellens, R., and Grandcolas, P. (2015). Phylogeny of Dictyoptera: Dating the Origin of Cockroaches, Praying Mantises and Termites with Molecular Data and Controlled Fossil Evidence. PLOS ONE, 10(7):e0130127.

Lehtinen, P. T. (1967). Classification of the cribellate spiders and some allied families, with notes on the evolution of the suborder Araneomorpha. In Annales zoologici fennici, pages 199-468. Societas Zoologica Botanica Fennica Vanamo.

Lemmon, A. R., Brown, J. M., Stanger-Hall, K., and Lemmon, E. M. (2009). The Effect of Ambiguous Data on Phylogenetic Estimates Obtained by Maximum Likelihood and Bayesian Inference. Systematic Biology, 58(1):130-145.

Lemmon, E. M. and Lemmon, A. R. (2013). High-Throughput Genomic Data in Systematics and Phylogenetics. Annual Review of Ecology, Evolution, and Systematics, 44(1):99-121.

Levi, H. W. (1980). Orb-webs: primitive or specialized. In Gruber, J., editor, Proceedings of the 8th International Congress of Arachnology, pages 367-370.

Li, L., Stoeckert, C. J., and Roos, D. S. (2003). OrthoMCL: identification of ortholog groups for eukaryotic genomes. Genome research, 13(9):2178-2189.

Liu, L. and Yu, L. (2011). Estimating Species Trees from Unrooted Gene Trees. Systematic Biology, 60(5):661-667.

McKenna, D. D., Sequeira, A. S., Marvaldi, A. E., and Farrell, B. D. (2009). Temporal lags and overlap in the diversification of weevils and flowering plants. Proceedings of the National Academy of Sciences, 106(17):7083-7088.

Mckenna, D. D., Wild, A. L., Kanda, K., Bellamy, C. L., Beutel, R. G., Caterino, M. S., Farnum, C. W., Hawks, D. C., Ivie, M. A., Jameson, M. L., et al. (2015). The beetle tree of life reveals that coleoptera survived end-permian mass extinction to diversify during the cretaceous terrestrial revolution. Systematic Entomology, 40(4):835-880.

Meyer, B., Meusemann, K., and Misof, B. (2011). MARE: MAtrix REduction-a tool to select optimized data subsets from supermatrices for phylogenetic inference. Bonn (Germany): Zentrum fuur molekulare Biodiversitätsforschung (zmb) am ZFMK.

Michalik, P. and Ramírez, M. J. (2014). Evolutionary morphology of the male reproductive system, spermatozoa and seminal fluid of spiders (Araneae, Arachnida) - Current knowledge and future directions. Arthropod Structure \& Development, 43(4):291-322.

Miller, J. A., Carmichael, A., Ramírez, M. J., Spagna, J. C., Haddad, C. R., Řezáč, M., Johannesen, J., Král, J., Wang, X.-P., and Griswold, C. E. (2010). Phylogeny of entelegyne spiders: Affinities of the family Penestomidae (NEW RANK), generic phylogeny of Eresidae, and asymmetric rates of change in spinning organ evolution (Araneae, Araneoidea, Entelegynae). Molecular Phylogenetics and Evolution, 55(3):786-804.

Mirarab, S., Reaz, R., Bayzid, M. S., Zimmermann, T., Swenson, M. S., and Warnow, T. (2014). ASTRAL: genome-scale coalescent-based species tree estimation. Bioinformatics, 30(17):i541-i548.

Misof, B., Liu, S., Meusemann, K., Peters, R. S., Donath, A., Mayer, C., Frandsen, P. B., Ware, J., Flouri, T., Beutel, R. G., and others (2014). Phylogenomics resolves the timing and pattern of insect evolution. Science, 346(6210):763-767.

Misof, B. and Misof, K. (2009). A Monte Carlo Approach Successfully Identifies Randomness in Multiple Sequence Alignments : A More Objective Means of Data Exclusion. Systematic Biology, 58(1):21-34.

Moreau, C. S. (2006). Phylogeny of the Ants: Diversification in the Age of Angiosperms. Science, 312(5770):101-104.

Opell, B. (1979). Revision of the genera and tropical American species of the spider family Uloboridae. 
Revisión de los géneros de las especies americanas tropicales de arañas de la familia Uloboridae. Bulletin of the Museum of Comparative Zoology., 148(10):443-549.

Opell, B. D. (1983). A review of the genus Tangaroa (Araneae, Uloboridae). Journal of Arachnology, pages 287-295.

Penalver, E. (2006). Early Cretaceous Spider Web with Its Prey. Science, 312(5781):1761-1761.

Penney, D. and Ortuño, V. M. (2006). Oldest true orb-weaving spider (Araneae: Araneidae). Biology Letters, 2(3):447-450.

Penney, D., Wheater, C. P., and Selden, P. A. (2003). Resistance of spiders to Cretaceous-Tertiary extinction events. Evolution, 57(11):2599-2607.

Platnick, N. I., Coddington, J. A., Forster, R. R., and Griswold, C. E. (1991). Spinneret Morphology and the Phylogeny of Haplogyne Spiders (Araneae, Araneomorphae). American Museum noviates, 3016.

Plummer, M., Best, N., Cowles, K., and Vines, K. (2006). CODA: Convergence diagnosis and output analysis for MCMC. $R$ news, 6(1):7-11.

Polotow, D., Carmichael, A., and Griswold, C. E. (2015). Total evidence analysis of the phylogenetic relationships of Lycosoidea spiders (Araneae, Entelegynae). Invertebrate Systematics, 29(2):124.

Price, M. N., Dehal, P. S., Arkin, A. P., and others (2010). FastTree 2-approximately maximum-likelihood trees for large alignments. PloS one, 5(3):e9490.

Prum, R. O., Berv, J. S., Dornburg, A., Field, D. J., Townsend, J. P., Lemmon, E. M., and Lemmon, A. R. (2015). A comprehensive phylogeny of birds (Aves) using targeted next-generation DNA sequencing. Nature, 526(7574):569-573.

Rabosky, D. L., Donnellan, S. C., Grundler, M., and Lovette, I. J. (2014). Analysis and Visualization of Complex Macroevolutionary Dynamics: An Example from Australian Scincid Lizards. Systematic Biology, 63(4):610-627.

Ramírez, M. J. (2000). Respiratory system morphology and the phylogeny of haplogyne spiders (Araneae, Araneomorphae). Journal of Arachnology, 28(2):149-157.

Ramírez, M. J. (2014). The morphology and phylogeny of dionychan spiders (Araneae: Araneomorphae). Bulletin of the American Museum of Natural History, 390(1):1-374.

Raven, R. J. (1985). The Spider Infraorder Mygalomorphae (Araneae): Cladistics and Systematics. Bulletin of the American Museum of Natural History, 182(1):1-184.

Rice, P., Longden, I., Bleasby, A., and others (2000). EMBOSS: the European molecular biology open software suite. Trends in genetics, 16(6):276-277.

Roure, B., Baurain, D., and Philippe, H. (2013). Impact of Missing Data on Phylogenies Inferred from Empirical Phylogenomic Data Sets. Molecular Biology and Evolution, 30(1):197-214.

Saez, N. J., Senff, S., Jensen, J. E., Er, S. Y., Herzig, V., Rash, L. D., and King, G. F. (2010). Spider-Venom Peptides as Therapeutics. Toxins, 2(12):2851-2871.

Sanderson, M. J. (2002). Estimating Absolute Rates of Molecular Evolution and Divergence Times: A Penalized Likelihood Approach. Molecular Biology and Evolution, 19(1):101 -109.

Sanggaard, K. W., Bechsgaard, J. S., Fang, X., Duan, J., Dyrlund, T. F., Gupta, V., Jiang, X., Cheng, L., Fan, D., Feng, Y., Han, L., Huang, Z., Wu, Z., Liao, L., Settepani, V., Thøgersen, I. B., Vanthournout, B., Wang, T., Zhu, Y., Funch, P., Enghild, J. J., Schauser, L., Andersen, S. U., Villesen, P., Schierup, M. H., Bilde, T., and Wang, J. (2014). Spider genomes provide insight into composition and evolution of venom and silk. Nature Communications, 5.

Schacht, K. and Scheibel, T. (2014). Processing of recombinant spider silk proteins into tailor-made materials for biomaterials applications. Current Opinion in Biotechnology, 29:62-69.

Scharff, N. and Coddington, J. A. (1997). A phylogenetic analysis of the orb-weaving spider family Araneidae (Arachnida, Araneae). Zoological Journal of the Linnean Society, 120(4):355-434.

Selden, P. A. (1996). First fossil mesothele spider, from the Carboniferous of France. Revue suisse de Zoologie, 2:585-96.

Selden, P. A. (2002). First British Mesozoic spider, from Cretaceous amber of the Isle of Wight, southern England. Palaeontology, 45:973-983.

Selden, P. A., Anderson, J. M., Anderson, H. M., and Fraser, N. C. (1999). Fossil araneomorph spiders from the Triassic of South Africa and Virginia. Journal of Arachnology, pages 401-414.

Selden, P. A. and Gall, J.-C. (1992). A Triassic mygalomorph spider from the northern Vosges, France. Palaeontology, 35:211-235.

Selden, P. A. and Penney, D. (2010). Fossil spiders. Biological Reviews, 85(1):171-206. 
Selden, P. A., Ren, D., and Shih, C. (2015). Mesozoic cribellate spiders (araneae: Deinopoidea) from china. Journal of Systematic Palaeontology, (ahead-of-print):1-26.

Selden, P. A., Shih, C., and Ren, D. (2013). A giant spider from the Jurassic of China reveals greater diversity of the orbicularian stem group. Naturwissenschaften, 100(12):1171-1181.

Spagna, J. C., Crews, S. C., and Gillespie, R. G. (2010). Patterns of habitat affinity and Austral/Holarctic parallelism in dictynoid spiders (Araneae:Entelegynae). Invertebrate Systematics, 24(3):238.

Spagna, J. C. and Gillespie, R. G. (2008). More data, fewer shifts: Molecular insights into the evolution of the spinning apparatus in non-orb-weaving spiders. Molecular Phylogenetics and Evolution, 46(1):347368.

Stamatakis, A. (2014). RAxML version 8: a tool for phylogenetic analysis and post-analysis of large phylogenies. Bioinformatics, 30(9):1312-1313.

Starrett, J., Garb, J. E., Kuelbs, A., Azubuike, U. O., and Hayashi, C. Y. (2012). Early events in the evolution of spider silk genes. PLoS One, 7(6):e38084.

Wahlberg, N., Wheat, C. W., and Peña, C. (2013). Timing and Patterns in the Taxonomic Diversification of Lepidoptera (Butterflies and Moths). PLoS ONE, 8(11):e80875.

Wang, B., Zhang, H., and Jarzembowski, E. A. (2013). Early Cretaceous angiosperms and beetle evolution. Frontiers in Plant Science, 4.

Ward, P. S. (2014). The Phylogeny and Evolution of Ants. Annual Review of Ecology, Evolution, and Systematics, 45(1):23-43.

Wood, H. M., Griswold, C. E., and Gillespie, R. G. (2012a). Phylogenetic placement of pelican spiders (Archaeidae, Araneae), with insight into evolution of the "neck" and predatory behaviours of the superfamily Palpimanoidea. Cladistics, 28(6):598-626.

Wood, H. M., Matzke, N. J., Gillespie, R. G., and Griswold, C. E. (2012b). Treating fossils as terminal taxa in divergence time estimation reveals ancient vicariance patterns in the palpimanoid spiders. Systematic Biology, page sys092.

World Spider Catalog (2016). World Spider Catalog, Version 17.0. Natural History Museum Bern.

Xia, X. (2014). Phylogenetic Bias in the Likelihood Method Caused by Missing Data Coupled with Among-Site Rate Variation: An Analytical Approach. In Hutchison, D., Kanade, T., Kittler, J., Kleinberg, J. M., Kobsa, A., Mattern, F., Mitchell, J. C., Naor, M., Nierstrasz, O., Pandu Rangan, C., Steffen, B., Terzopoulos, D., Tygar, D., Weikum, G., Basu, M., Pan, Y., and Wang, J., editors, Bioinformatics Research and Applications, volume 8492, pages 12-23. Springer International Publishing, Cham. 
Table 1. Major spider lineages referenced throughout the text. Superscripts (column 1) reference node labels in Figure 1 (summary of family level relationships).

\begin{tabular}{|c|c|c|}
\hline Lineage & Composition and Placement & Description/Characteristics \\
\hline${ }^{1}$ Araneae & All spiders & $\begin{array}{l}\text { Cosmopolitan; cheliceral venom glands, } \\
\text { ability to produce silk from abdominal silk } \\
\text { glands; male pedipalps modified for sperm } \\
\text { transfer }\end{array}$ \\
\hline${ }^{2}$ Mesothelae & $\begin{array}{l}\text { Plesiomorphic sister group to all liv- } \\
\text { ing spiders }\end{array}$ & $\begin{array}{l}\text { SE Asia; mid ventrally positioned spin- } \\
\text { nerets; distinct dorsal abdominal tergites, } \\
\text { very narrow sternum }\end{array}$ \\
\hline${ }^{3}$ Opisthothelae & The two major spider lineages & $\begin{array}{l}\text { Typical terminal spinneret placement and } \\
\text { sternal morphology }\end{array}$ \\
\hline${ }^{4}$ Mygalomorphae & $\begin{array}{l}\text { Trapdoor, baboon and funnel spi- } \\
\text { ders, tarantulas, and their kin }\end{array}$ & $\begin{array}{l}\text { Paraxial chelicerae with venom glands; } \\
\text { most lead sedentary lives in burrows; lack } \\
\text { anterior median spinnerets; often large and } \\
\text { hirsute; two pairs of book lungs }\end{array}$ \\
\hline${ }^{5}$ Atypoidina & $\begin{array}{l}\text { Sister group to remaining mygalo- } \\
\text { morphs }\end{array}$ & $\begin{array}{l}\text { Most species with vestigial abdominal ter- } \\
\text { gites and unique modifications to male pedi- } \\
\text { palp }\end{array}$ \\
\hline${ }^{6}$ Aviculariodea & All remaining mygalomorph taxa & $\begin{array}{l}\text { Includes major mygalomorph families, } \\
\text { nearly half of which are likely not mono- } \\
\text { phyletic }\end{array}$ \\
\hline${ }^{7}$ Theraphosoidina & $\begin{array}{l}\text { Comprises families Theraphosidae } \\
\text { and Barychelidae }\end{array}$ & $\begin{array}{l}\text { Includes the typically large and hirsute } \\
\text { tarantulas and baboon spiders }\end{array}$ \\
\hline${ }^{8}$ Araneomorphae & Over $90 \%$ of all spider diversity & $\begin{array}{l}\text { Anterior median spinnerets fused to form a } \\
\text { cribellum (later lost multiple times) }\end{array}$ \\
\hline${ }^{9}$ Paleocribellatae & $\begin{array}{l}\text { Comprises single family Hypochili- } \\
\text { dae; hypothesized sister group to all } \\
\text { other araneomorphs }\end{array}$ & $\begin{array}{l}\text { Hypochilid synapomorphies, e.g., che- } \\
\text { liceral depression; also retain a number of } \\
\text { primitive traits including two pairs of book- } \\
\text { lungs }\end{array}$ \\
\hline Neocribellatae & Remaining spider lineages & $\begin{array}{l}\text { Paracribellum (complimentary spinning } \\
\text { field to cribellum); extension of venom } \\
\text { gland into prosoma }\end{array}$ \\
\hline Austrochiliodea & $\begin{array}{l}\text { Families Austrochilidae and Gradun- } \\
\text { gulidae; sister group to all other } \\
\text { neocribellate lineages }\end{array}$ & $\begin{array}{l}\text { Gondwanan taxa with notched tarsal organs; } \\
\text { typically with two pairs of booklungs - pos- } \\
\text { terior pair modified as tracheae in some taxa }\end{array}$ \\
\hline${ }^{10}$ Haplogynae & $\begin{array}{l}\text { Neocribellate lineage with simple } \\
\text { genitalia; includes spitting spiders } \\
\text { and cellar spiders }\end{array}$ & $\begin{array}{l}\text { Spinnerets lack tartipores; mating with } \\
\text { palps inserted simultaneously; in some taxa } \\
\text { female genital opening lacks an epigynum; } \\
\text { chelicerae fused at base, synspermia, male } \\
\text { palpal organ simple }\end{array}$ \\
\hline${ }^{11}$ Entelegynae & $\begin{array}{l}\text { Comprises all remaining spider lin- } \\
\text { eages with complex genitalia }\end{array}$ & $\begin{array}{l}\text { Female genitalia with a "flow through sys- } \\
\text { tem" of separate copulatory and fertilization } \\
\text { ducts; male palpal organ typically under hy- } \\
\text { draulic control }\end{array}$ \\
\hline
\end{tabular}


Table 1 - continued from previous page

\begin{tabular}{|c|c|c|}
\hline Lineage & Composition and Placement & Description/Characteristics \\
\hline Palpimanoidea & $\begin{array}{l}\text { Comprises a number of enigmatic } \\
\text { families }\end{array}$ & $\begin{array}{l}\text { Araneophages with lateral scopulae on an- } \\
\text { terior legs }\end{array}$ \\
\hline Eresoidea & $\begin{array}{l}\text { Includes } 3 \text { families: Eresidae, Her- } \\
\text { siliidae, Oecobiidae; sister to re- } \\
\text { maining entelegynes }\end{array}$ & $\begin{array}{l}\text { Controversial superfamily; oecobiids and } \\
\text { hersiliids share a unique attack behavior }\end{array}$ \\
\hline Orbiculariae & $\begin{array}{l}\text { Comprises the Deinopoidea and Ara- } \\
\text { neoidea }\end{array}$ & $\begin{array}{l}\text { Members of this lineage include cribellate } \\
\text { and ecribellate orb-web weavers as well as } \\
\text { derived araneoids that use adhesive threads } \\
\text { to construct sheet and cob-webs }\end{array}$ \\
\hline Deinopoidea & $\begin{array}{l}\text { Includes the cribellate orbicularian } \\
\text { families Uloboridae and Deinopidae }\end{array}$ & $\begin{array}{l}\text { Construct cribellate orb web; long con- } \\
\text { sidered sister group to adhesive orb web } \\
\text { weavers on basis of behavioral web con- } \\
\text { struction data }\end{array}$ \\
\hline 12 Araneoidea & $\begin{array}{l}\text { Spider superfamily that includes ad- } \\
\text { hesive orb web weaving taxa and } \\
\text { others }\end{array}$ & $\begin{array}{l}\text { Members of this lineage all use adhesive } \\
\text { threads; monophyly supported by a number } \\
\text { of spinning and other morphological char- } \\
\text { acteristics }\end{array}$ \\
\hline 13 RTA & $\begin{array}{l}\text { Large diverse lineage of spiders that } \\
\text { includes wolf, jumping, running, } \\
\text { fishing, and crab spiders }\end{array}$ & $\begin{array}{l}\text { Defined primarily by the presence of a pro- } \\
\text { jection on the male palp - the retrolateral } \\
\text { tibial apophysis (RTA) }\end{array}$ \\
\hline 14 Dionycha & $\begin{array}{l}\text { Subclade of the RTA lineage, com- } \\
\text { prises about } 1 / 3 \text { of all spider diver- } \\
\text { sity }\end{array}$ & $\begin{array}{l}\text { Defined as a group based on their two } \\
\text { clawed condition with flanking tufts of se- } \\
\text { tae for adhesion to smooth surfaces }\end{array}$ \\
\hline Lycosoidea & $\begin{array}{l}\text { Large superfamily comprising } 10 \\
\text { families including fishing and wolf } \\
\text { spiders }\end{array}$ & $\begin{array}{l}\text { Monophyly of this superfamily is based on } \\
\text { a number of morphological features (not } \\
\text { universal) including a grate-shaped tapetum, } \\
\text { an oval-shaped calamistrum, and male pal- } \\
\text { pal features }\end{array}$ \\
\hline
\end{tabular}


Table 2. Summary of all phylogenomic analyses. Data matrix numbers correspond to Figure 2, inset.

\begin{tabular}{|c|c|c|c|c|c|c|}
\hline Data Set & \#OGs & \#AAs & $\%$ missing & \#reps & Log Likelihood & Notes \\
\hline (1) All genes & 3,398 & 696,652 & $38.5 \%$ & 225 & - 20949310.821967 & ExaML AUTOF \\
\hline (2) 1 st reduce & 1,699 & 410,717 & $26.0 \%$ & 300 & $\begin{array}{l}- \\
14297508.033111\end{array}$ & ExaML AUTOF \\
\hline (3) 2 nd reduce & 850 & 230,582 & $19.6 \%$ & 300 & -8098715.107390 & ExaML AUTOF \\
\hline (4) $\mathrm{BCC}$ & 1,699 & 311,756 & $33.6 \%$ & 300 & $\begin{array}{l}- \\
10017456.343941\end{array}$ & ExaML AUTOF \\
\hline $\begin{array}{l}\text { (5) Arthropod } \\
\text { core OG }\end{array}$ & 549 & 107,307 & $33.0 \%$ & 1000 & -2729523.038858 & $\begin{array}{l}\text { ExaML AUTOF } \\
\text { bs in RAxML }\end{array}$ \\
\hline $\begin{array}{l}\text { (6) } 74 \text { taxa (- } \\
\text { Stegodyphus) }\end{array}$ & 3,398 & 629,566 & $38.8 \%$ & 300 & $\begin{array}{l}- \\
20569138.970981\end{array}$ & ExaML AUTOF \\
\hline $\begin{array}{l}\text { (7) MARE ( } 58 \\
\text { taxa, } 55 \text { in- } \\
\text { group) }\end{array}$ & 1,488 & 351,333 & $19.6 \%$ & 295 & -9227466.065087 & ExaML AUTOF \\
\hline (8) ASTRAL & 3,398 & & & 100 & & $\begin{array}{l}100 \text { bootstrap } \\
\text { reps per parti- } \\
\text { tion }\end{array}$ \\
\hline
\end{tabular}


Table 3. Posterior probabilities (PP), ages (Ma), and 95\% confidence intervals (CI) for the highest posterior density (HPD) recovered by the BEAST analysis. Node numbers correspond to Figure 5. Node numbers in bold correspond to numbers in Figure 1 and Table 1.

\begin{tabular}{|c|c|c|c|}
\hline Node & Age & HPD $95 \% \mathrm{CI}$ & Taxonomic Group \\
\hline 1 & 340 & $287-398$ & Araneae \\
\hline 3 & 309 & $258-365$ & Opistothele \\
\hline 4 & 261 & 218-307 & Mygalomorphae \\
\hline 5 & 108 & $49-192$ & Atypoidina \\
\hline 6 & 114 & $57-197$ & Avicularoidea \\
\hline 7 & 47 & $2-125$ & Theraphosoidina \\
\hline 8 & 276 & $223-330$ & Opistothelae \\
\hline 10 & 190 & $121-262$ & Haplogynae \\
\hline 11 & 214 & $154-280$ & Entelegynae \\
\hline 12 & 170 & $114-233$ & Araneoidea \\
\hline 13 & 139 & $83-201$ & RTA \\
\hline 14 & 86 & $40-139$ & Dionycha \\
\hline 15 & 218 & $53-389$ & \\
\hline 16 & 37 & $2-109$ & \\
\hline 17 & 79 & $18-163$ & \\
\hline 18 & 162 & $85-257$ & \\
\hline 19 & 93 & $47-151$ & \\
\hline 20 & 71 & $25-127$ & \\
\hline 21 & 48 & $35-217$ & Ctenizidae \\
\hline 22 & 232 & $165-299$ & \\
\hline 23 & 160 & $49-254$ & \\
\hline 24 & 158 & $85-232$ & \\
\hline 25 & 101 & $28-179$ & \\
\hline 26 & 81 & $23-148$ & Pholcidae \\
\hline 27 & 197 & $137-263$ & \\
\hline 28 & 92 & $26-172$ & Theridiidae \\
\hline 29 & 148 & $96-208$ & \\
\hline 30 & 127 & $75-186$ & \\
\hline 31 & 100 & $44-160$ & \\
\hline 32 & 64 & $15-123$ & Tetragnathidae \\
\hline 33 & 130 & $81-186$ & \\
\hline
\end{tabular}


Table 3 - continued from previous page

\begin{tabular}{|c|c|c|c|}
\hline Node & Age & HPD $95 \% \mathrm{CI}$ & Taxonomic Group \\
\hline 34 & 107 & $52-165$ & \\
\hline 35 & 76 & $25-131$ & \\
\hline 36 & 94 & 49-149 & \\
\hline 37 & 61 & $22-116$ & Araneidae \\
\hline 38 & 33 & $29-312$ & \\
\hline 39 & 41 & $33-420$ & \\
\hline 40 & 191 & $134-258$ & \\
\hline 41 & 152 & $64-228$ & \\
\hline 42 & 21 & $28-126$ & Uloboridae \\
\hline 43 & 174 & $117-242$ & \\
\hline 44 & 112 & $60-174$ & \\
\hline 45 & 44 & $4-113$ & \\
\hline 46 & 92 & $44-149$ & \\
\hline 47 & 74 & $29-126$ & \\
\hline 48 & 47 & $34-243$ & \\
\hline 49 & 120 & $68-182$ & \\
\hline 50 & 104 & $57-160$ & \\
\hline 51 & 71 & $28-121$ & \\
\hline 52 & 52 & $36-130$ & \\
\hline 53 & 70 & $28-120$ & Lycosoidea \\
\hline 54 & 50 & $35-735$ & \\
\hline 55 & 49 & $15-93$ & \\
\hline 56 & 37 & $27-211$ & \\
\hline
\end{tabular}




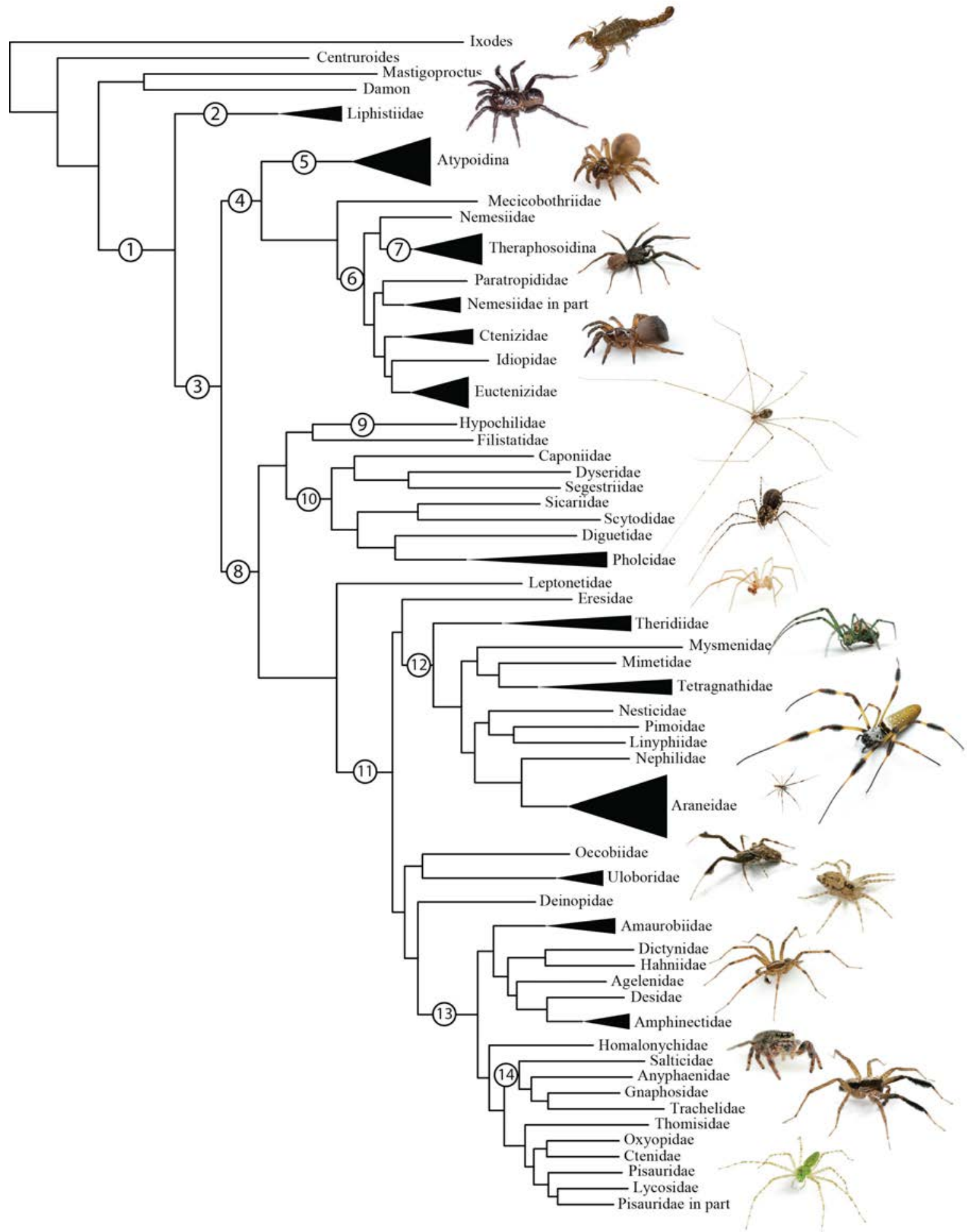

Figure 1. Summary, preferred tree, of spider relationships based on phylogenomic analyses shown in Figure 2. Numbers at nodes correspond to superscripts in Table 1. Images in descending order: Scorpion, Mesothelae, Antrodiaetidae, Paratropopididae, Ctenizidae, Pholcidae, Scytodidae, Theridiidae, Tetragnathidae, Nephilidae ( $0^{7}$ and + ), Uloboridae, Oecobiidae, Agelenidae, Salticidae, Lycosidae, Oxyopidae. 


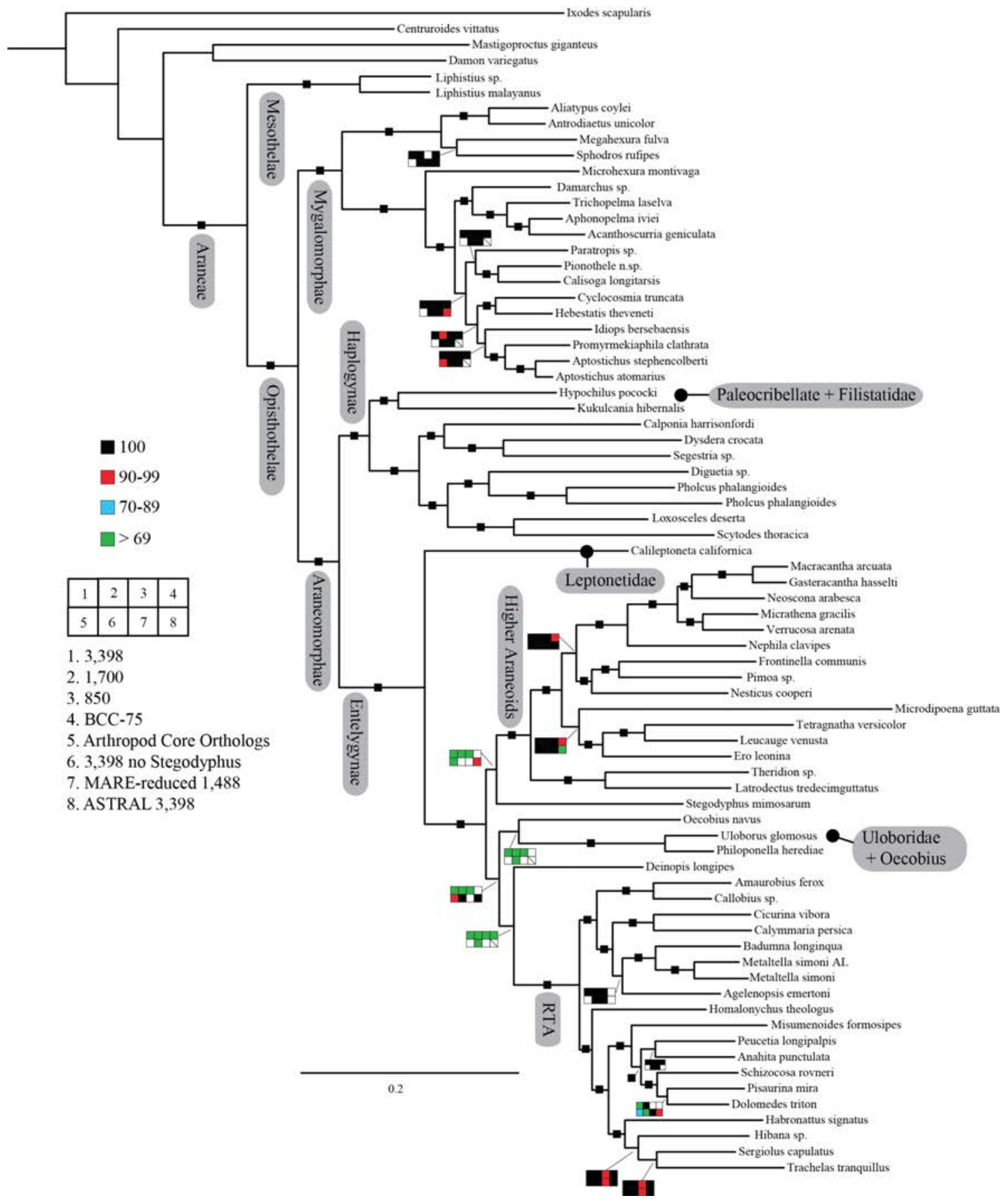

Figure 2. Summary of phylogenomic analyses (different matrices outlined in Table 2) on the phylogenetic hypothesis based on ExaML analysis of dataset 1 (3,398 OGs). Box plots indicate bootstrap value ranges for each node across matrices 1-7; single solid blocks indicate bootstrap values of $100 \%$ in all analyses. 


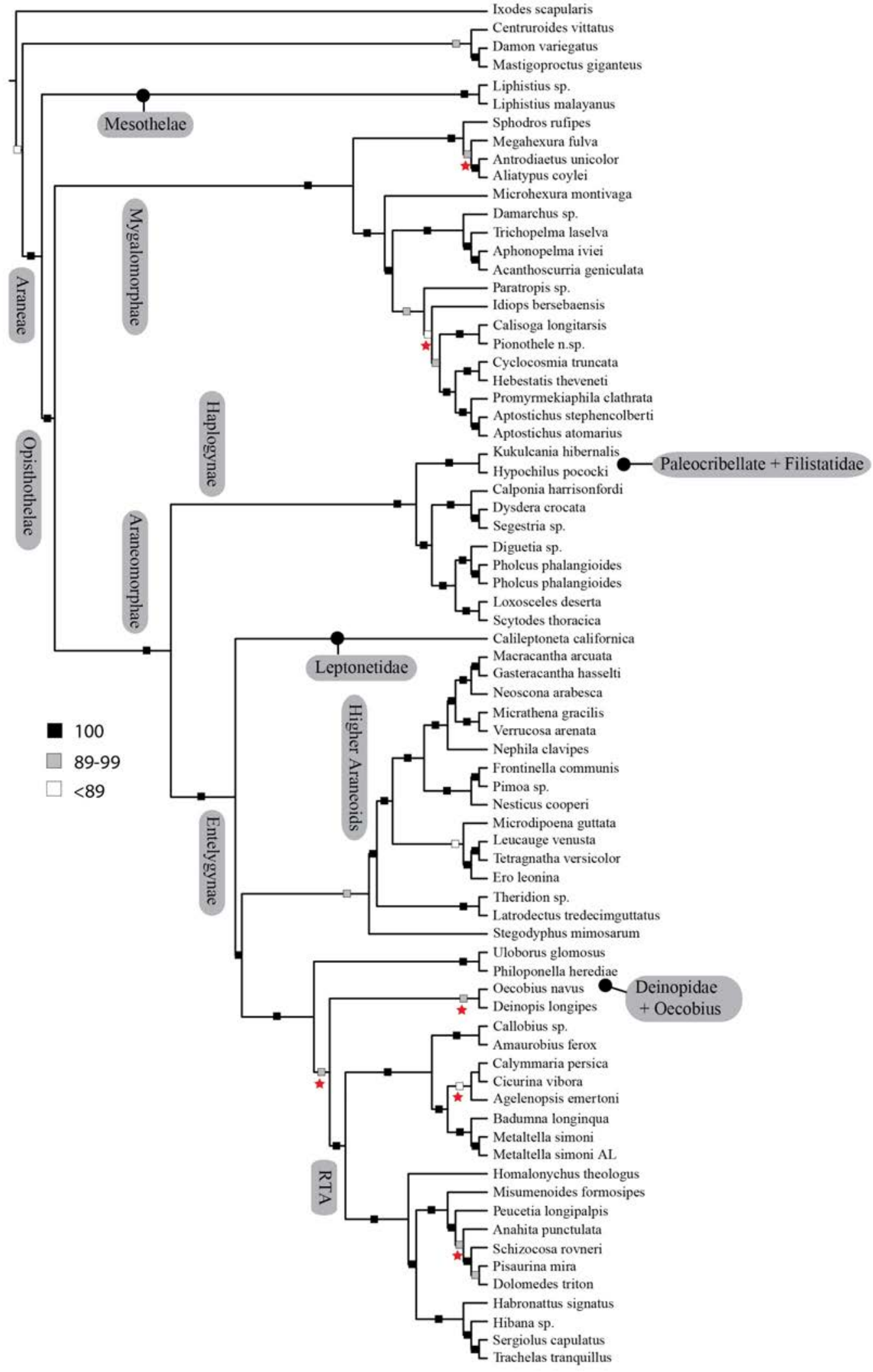

Figure 3. ASTRAL gene tree analysis of spider relationships based on 3,398 genes. Relative support value ranges reported at each node (inset legend); red stars indicate branches not congruent with tree shown in Figures 1, 2. 


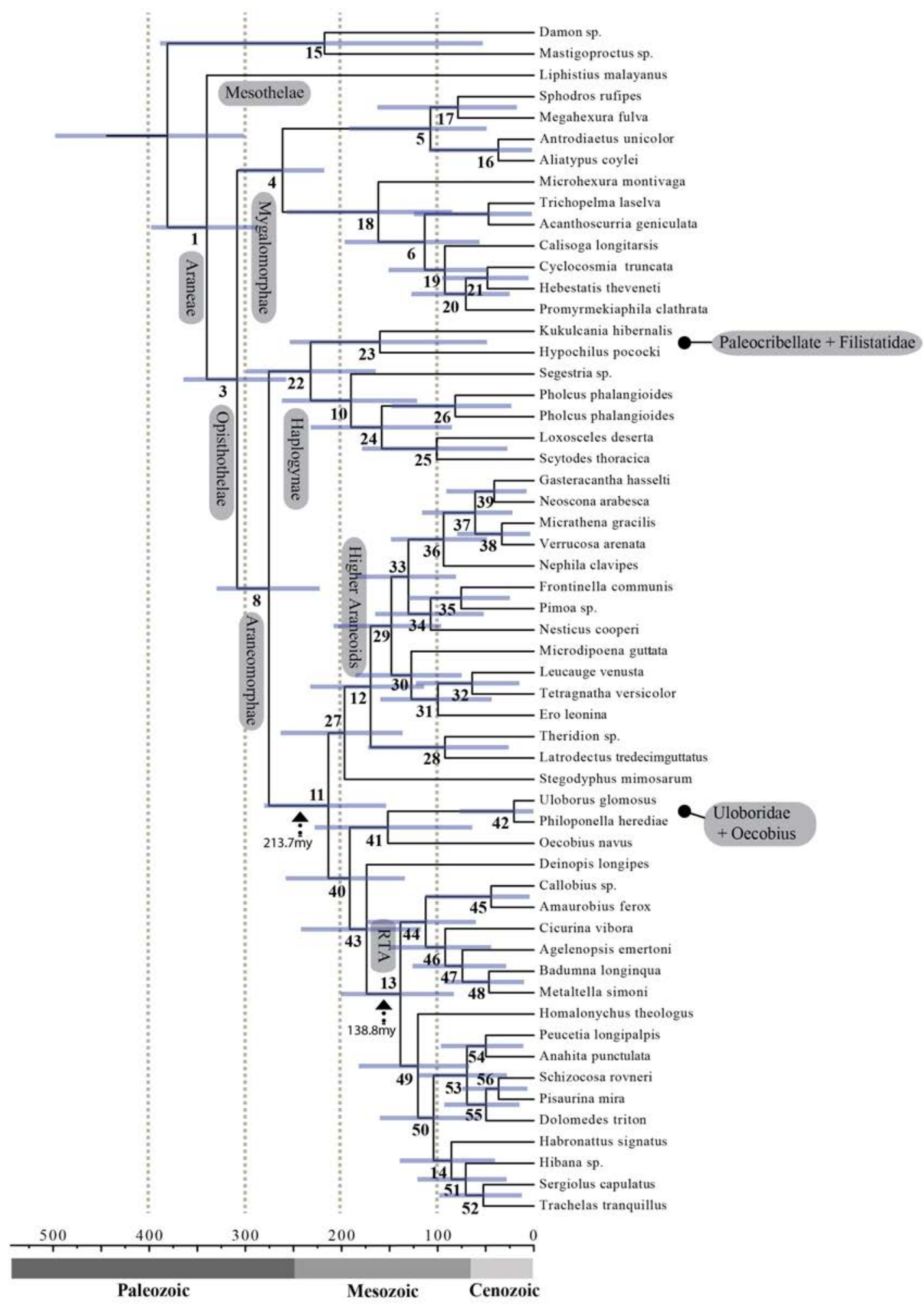

Figure 4. Chronogram resulting from two Bayesian MCMC runs performed in BEAST showing estimated divergence time for major spider lineages. Time scale on $\mathrm{x}$ axis; node point estimates and $95 \%$ confidence intervals (blue bars) are reported in Table 2. 


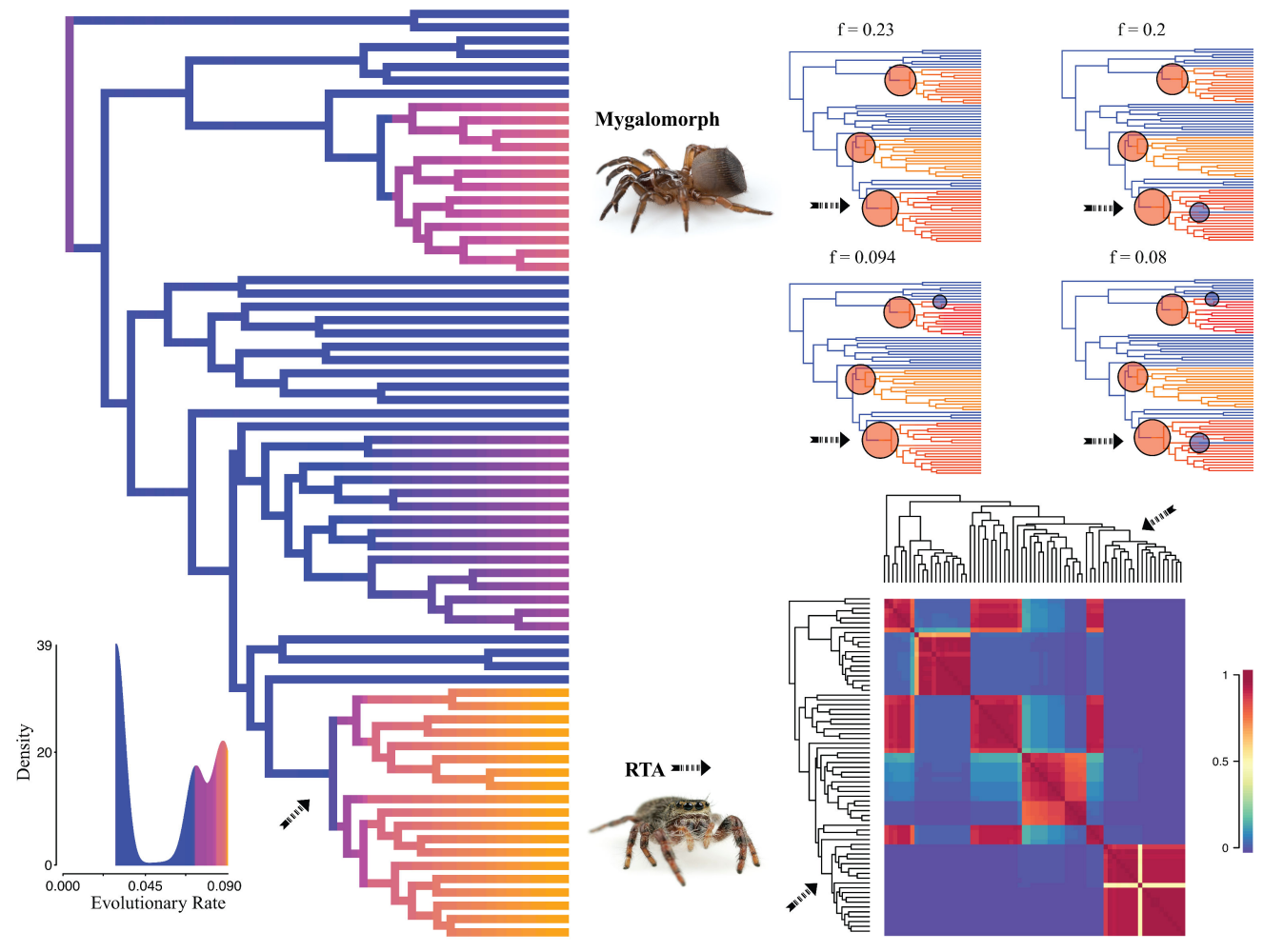

Figure 5. Time-calibrated phylogeny of spiders with branches colored by reconstructed net diversification rates (lower left). Rates on branches are means of the marginal densities of branch-specific rates. Inset histogram shows posterior density of speciation rates. Smaller phylogenies (top right) show the four distinct shift configurations with the highest posterior probability. For each distinct shift configuration, the locations of rate shifts are shown as red (rate increases) and blue (rate decreases) circles, with circle size proportional to the marginal probability of the shift. The macroevolutionary cohort analysis (lower right) displays the pairwise probability that any two species share a common macroevolutionary rate dynamic. Dashed arrow indicates position of RTA clade on each tree. 


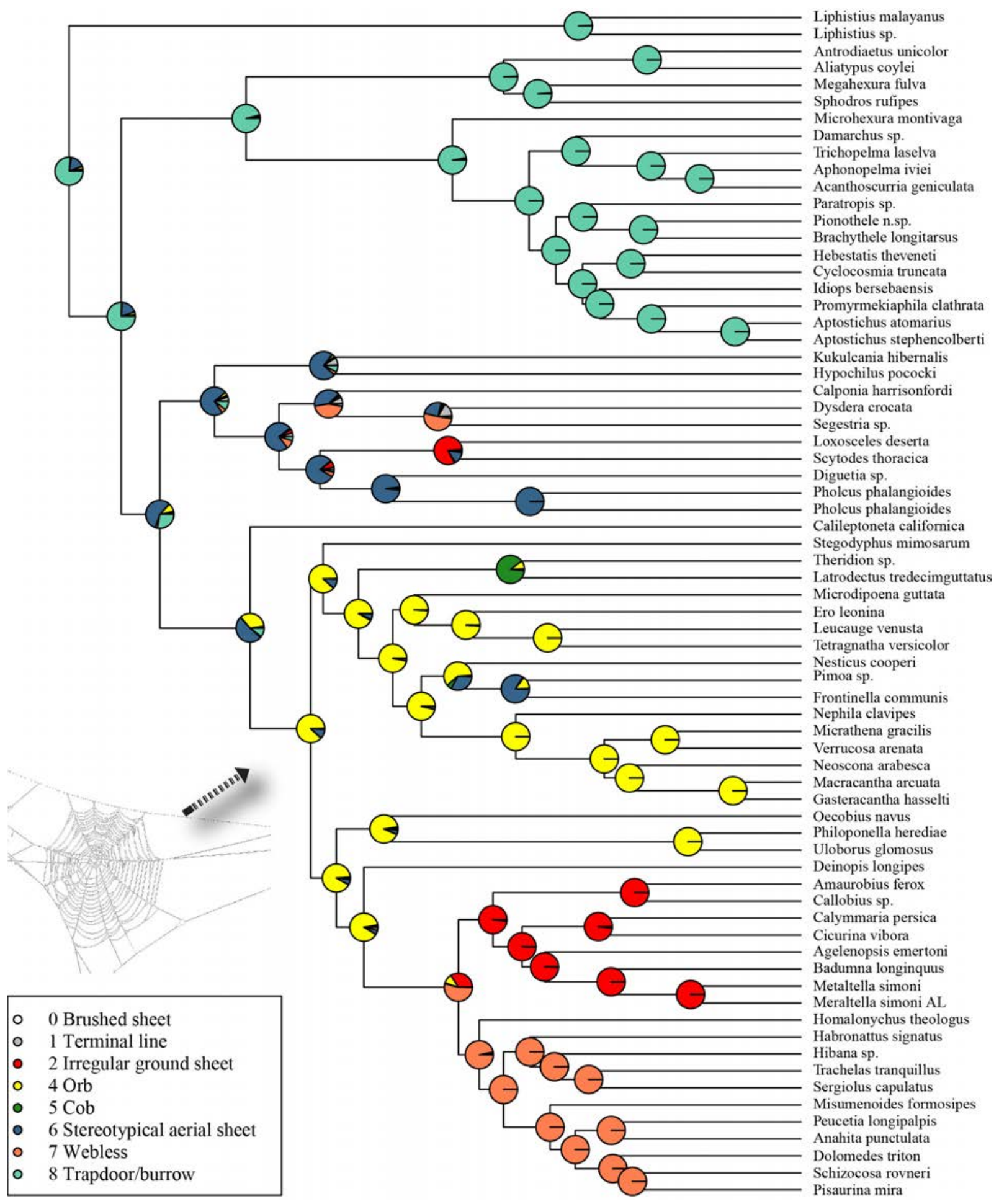

Figure 6. ML ancestral state reconstructions of web type on the time-calibrated phylogeny of spiders. Circle areas correspond to probability of ancestral states. The arrow points to one of the main diversification rate shifts reconstructed by BAMM at the MRCA of Entelegynae excluding Leptonetidae. 